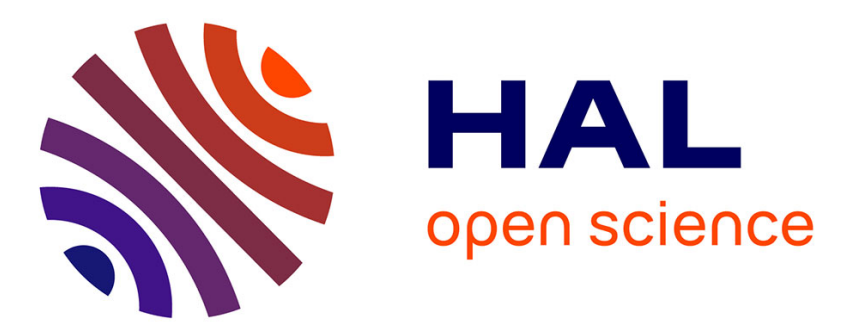

\title{
Dynamics of solitary waves observed over the North Indian Ocean during the Indian Ocean Experiment (INDOEX) 1999
}

André Szantai, Philippe Drobinski, Françoise Désalmand

\section{To cite this version:}

André Szantai, Philippe Drobinski, Françoise Désalmand. Dynamics of solitary waves observed over the North Indian Ocean during the Indian Ocean Experiment (INDOEX) 1999. Journal of Geophysical Research: Atmospheres, 2011, 116 (5), pp.D05115. 10.1029/2010JD014877 . hal-01119139

\author{
HAL Id: hal-01119139 \\ https://hal.science/hal-01119139
}

Submitted on 21 Feb 2015

HAL is a multi-disciplinary open access archive for the deposit and dissemination of scientific research documents, whether they are published or not. The documents may come from teaching and research institutions in France or abroad, or from public or private research centers.
L'archive ouverte pluridisciplinaire HAL, est destinée au dépôt et à la diffusion de documents scientifiques de niveau recherche, publiés ou non, émanant des établissements d'enseignement et de recherche français ou étrangers, des laboratoires publics ou privés. 


\title{
Dynamics of solitary waves observed over the North Indian Ocean during the Indian Ocean Experiment (INDOEX) 1999
}

\author{
André Szantai, ${ }^{1}$ Philippe Drobinski, ${ }^{1}$ and Françoise Désalmand ${ }^{2}$ \\ Received 10 August 2010; revised 2 December 2010; accepted 3 January 2011; published 10 March 2011.
}

[1] During the Indian Ocean Experiment (INDOEX) experiment (January-March 1999), mesoscale solitary waves have been observed and tracked over the North Indian Ocean on a series of Meteosat- 5 satellite images. These solitary waves have a horizontal wavelength of $10-15 \mathrm{~km}$ and propagate westward at low level at a speed of $10-18 \mathrm{~m} / \mathrm{s}$. Unlike similar wave phenomena observed mainly over land, they have a long lifetime, which can exceed $48 \mathrm{~h}$. A key element explaining the existence and longevity of the solitary waves is the presence of an inversion layer, acting as a waveguide and separating the boundary layer into two sublayers: a lower layer over the ocean (marine boundary layer) and an upper layer originating from the Indian subcontinent (land plume layer). Profiles from radiosondes launched from the Ron Brown and from dropsondes from the Hercules C-130 airplane helped to determine this waveguide structure. A suggested mechanism leading to the generation of solitary waves is a collision between the sea breeze in the vicinity of the West Indian coast and the easterly/northeasterly winter monsoon winds, with a possible contribution of convection reinforced by topography (Western Ghats range), during the local afternoon. Another phenomenon related to sea breeze and local convection in this coastal area, the injection of "bubbles" of moisture into the drier upper boundary layer, has also been identified on European Centre for Medium-Range Weather Forecasts analyses. These bubbles form daily during the afternoon and drift westward over the North Indian Ocean at latitudes around $12^{\circ} \mathrm{N}$ and progressively subside and dissipate or become integrated into larger air masses.

Citation: Szantai, A., P. Drobinski, and F. Désalmand (2011), Dynamics of solitary waves observed over the North Indian Ocean during the Indian Ocean Experiment (INDOEX) 1999, J. Geophys. Res., 116, D05115, doi:10.1029/2010JD014877.

\section{Introduction}

[2] The propagation of mesoscale solitary waves in the lower troposphere has been observed in various regions of the world. These waves still constitute potential hazard for aviation security, in particular during takeoff and landing phases [Bieringer et al., 2004]. A more fundamental reason to investigate solitary waves is their influence on local or regional climate: such waves, or the atmospheric flows related to them or which generated them, can trigger the formation or enhance the growth of clouds and thus have an impact on the radiative balance.

[3] From a fluid mechanics point of view, the "solitary wave" term corresponds to atmospheric nonlinear wave disturbances, which are composed of one propagating leading wave, generally followed by smaller waves of decreasing amplitude. Undular bores are a particular type of nonlinear wave disturbances, associated with a jump in the

\footnotetext{
${ }^{1}$ Laboratoire de Météorologie Dynamique/IPSL, Ecole Polytechnique, Palaiseau, France.

${ }^{2}$ Laboratoire de Météorologie Dynamique/IPSL, Université Pierre et Marie Curie, Paris, France.

Copyright 2011 by the American Geophysical Union. 0148-0227/11/2010JD014877
}

height of the interface between different atmospheric layers before and after the passage of the event.

[4] Observations of solitary waves in the troposphere can be separated into two main groups [Rottman and Grimshaw, 2002]: solitary waves of small horizontal wavelength, about $1-10 \mathrm{~km}$, which propagate in the lower layers of the troposphere, at typical speeds of 10-20 m/s; and solitary waves of larger wavelength (100-500 km), which can have an important vertical extension up to the tropopause and propagate at higher speeds. Different observations of solitary waves of both types and their generation mechanism have been reviewed by Romanova and Yakushkin [1995]. The present text focuses on waves of the first group.

[5] Several mechanisms leading to the formation of tropospheric propagating solitary waves have been identified. One is the outflow of cold air masses from thunderstorms, leading to the formation of undular bores. Cases of solitary waves generated by thunderstorms have been observed over and around Oklahoma [see, e.g., Fulton et al., 1990; Koch et al., 2008]. Another mechanism is the presence of a cold front. Southerly morning glories generated over central Australia and propagating northward are representative of this case [Christie et al., 1981; Smith et al., 1995]. A third mechanism is collisions between sea breezes. The best known 
example are the northerly morning glories, generated by a collision between easterly and westerly sea breezes over Cape York (northeast Australia) and which propagate south/ southeastward over the Gulf of Carpentaria and northern Australia [Clarke, 1984; Smith, 1988; Goler and Reeder, 2004].

[6] During the winter months (December-April), anthropogenic haze is observed over the North Indian Ocean and South and Southeast Asia. The Indian Ocean Experiment (INDOEX) was designed in order to observe the effects of this pollution on the chemistry and the radiative forcing over this region [Ramanathan et al., 1995, 2001]. During this experiment, which took place from January to March 1999, westward moving cloud lines have been identified and tracked over the North Indian Ocean [Désalmand et al., 2003] (hereafter labeled DSPD2003). Associated with a motion at a higher speed than the surrounding analyzed wind, the presence of several parallel cloud lines of increasing brightness temperature (or decreasing albedo) with a wavelike pattern observed on geostationary satellite images suggested the existence of a solitary wave. At this stage, the nature of these propagating patterns of cloud lines, separated by a distance of $2-10 \mathrm{~km}$, and their generation mechanism was unknown. Similarities in aspect and behavior had nevertheless been noticed with morning glories, which are composed by one or several long bands of clouds associated with a solitary wave traveling over North Australia [Clarke, 1972; Smith, 1988; Christie, 1992].

[7] A similar type of wave pattern has previously been identified on Space Shuttle images from April 1993 over the northern Arabian Sea, and tentatively associated with a solitary wave packet [Zheng et al., 1998a]. Nineteen undular cloud lines with a separation of about $1 \mathrm{~km}$ have been observed, their aspect and spacing can be approximated by a theoretical solution of a wave propagation equation (dnoidal solution of the Korteweg-de Vries equation). Suggested mechanisms for their generation during the night are land breeze or katabatic flow from mountains in the Makran Coastal Range of Pakistan.

[8] In a recent study, numerous cases of wave patterns consistent with propagating gravity waves have also been detected over the Southwestern Indian Ocean, in the Mozambique Channel [da Silva and Magalhães, 2009], mainly during the local winter period (July-October). Wave patterns with typically 5 to 25 oscillations could be identified on images from MODIS and MERIS imagers (from Sun-synchronous satellites Terra/Aqua, and ENVISAT), and on SAR images from the ASAR instrument on board ENVISAT. Typical wavelengths of $1-16 \mathrm{~km}$ have been measured. Two generation mechanisms have been suggested: the arrival of anticyclonic air masses from high latitudes, which can be viewed as large-scale gravity currents, and a sea breeze system over Madagascar, possibly related to the island's topography.

[9] The results based on conventional meteorological and complementary satellite data presented hereafter reinforced our intuition that the line cloud bands observed in the DSPD2003 study are the visible parts of a solitary wave. Therefore we will use this term (and justify its use) in the following text.

[10] The study presented here focuses on solitary waves generated in the vicinity of the West Indian coast and which propagate westward over the North Indian Ocean during more than $48 \mathrm{~h}$ in some cases. In the previous, DSPD2003 article, cloud bands with a solitary wave pattern have been identified daily on series of images from the geostationary satellite Meteosat-5 during 4 periods: 15 January, 16-19 February, 27 February to 7 March, and 1-3 April 1999. These consecutive cloud lines are located at low level, are separated by a distance of $2-10 \mathrm{~km}$ and their length can reach several hundred kilometers.

[11] The current study completes it with a more precise description of the observed wave pattern (Figure 1). The first objective of the current study is to determine the characteristics of these solitary waves with the help of complementary observations, and to explain these measurements in relation to their environment. In particular, the longevity of these solitary waves observed over the ocean, which can exceed $24 \mathrm{~h}$, and the traveled distance over the ocean are exceptional, although cases of long-lasting solitary waves with an important part of their trajectory over land have been observed in other parts of the world. In order to measure this long lifetime and explain the mechanisms leading to their formation, persistence and decay, the current study takes advantages from two major qualities of Meteosat -5 image data: its availability at high frequency (one image every $1 / 2 \mathrm{~h}$ ) and the coverage of a large, mainly oceanic area not covered by conventional measurements. The second objective of this study is to present a generation mechanism for solitary waves, in relation with the regional atmospheric circulation, which includes sea breezes.

[12] In section 2, we will show observations of mesoscale atmospheric solitary waves made from satellites and surface stations (research vessels), and characteristics derived along their trajectory. In section 3, conditions and factors enabling the propagation of solitary waves, in particular waveguide conditions, will be presented. We will also suggest mechanisms explaining the formation of solitary waves and their relation with moisture and sea breezes. Section 4 presents the analogy between the observed solitary waves and Australian morning glories, and summarizes the generating mechanism, the phases of the lifecycle and favorable propagation conditions of North Indian Ocean solitary waves.

\section{Observations of Solitary Waves During INDOEX}

[13] The current section is focused on solitary waves of the third period, and more precisely on the 3-7 March 1999 cases. It also completes the detailed study on 6 March started in the DSPD2003 article. During these 5 days, the observed solitary waves had a similar behavior under close meteorological conditions. In the following sections, the cases are labeled by the day of their first, doubtless identification on satellite images in Indian Standard time (IST, i.e., $\mathrm{UTC}+5 \mathrm{~h} 30 \mathrm{~min}$ ), which corresponds in practice to the day before in UTC.

\subsection{Satellite Observations of Solitary Waves}

[14] A careful observation of series of Meteosat-5 images enabled us to describe the life cycle of solitary waves. Although their aspect varies a little from day to day, and also their duration, a common pattern has been identified (Figure 2). 


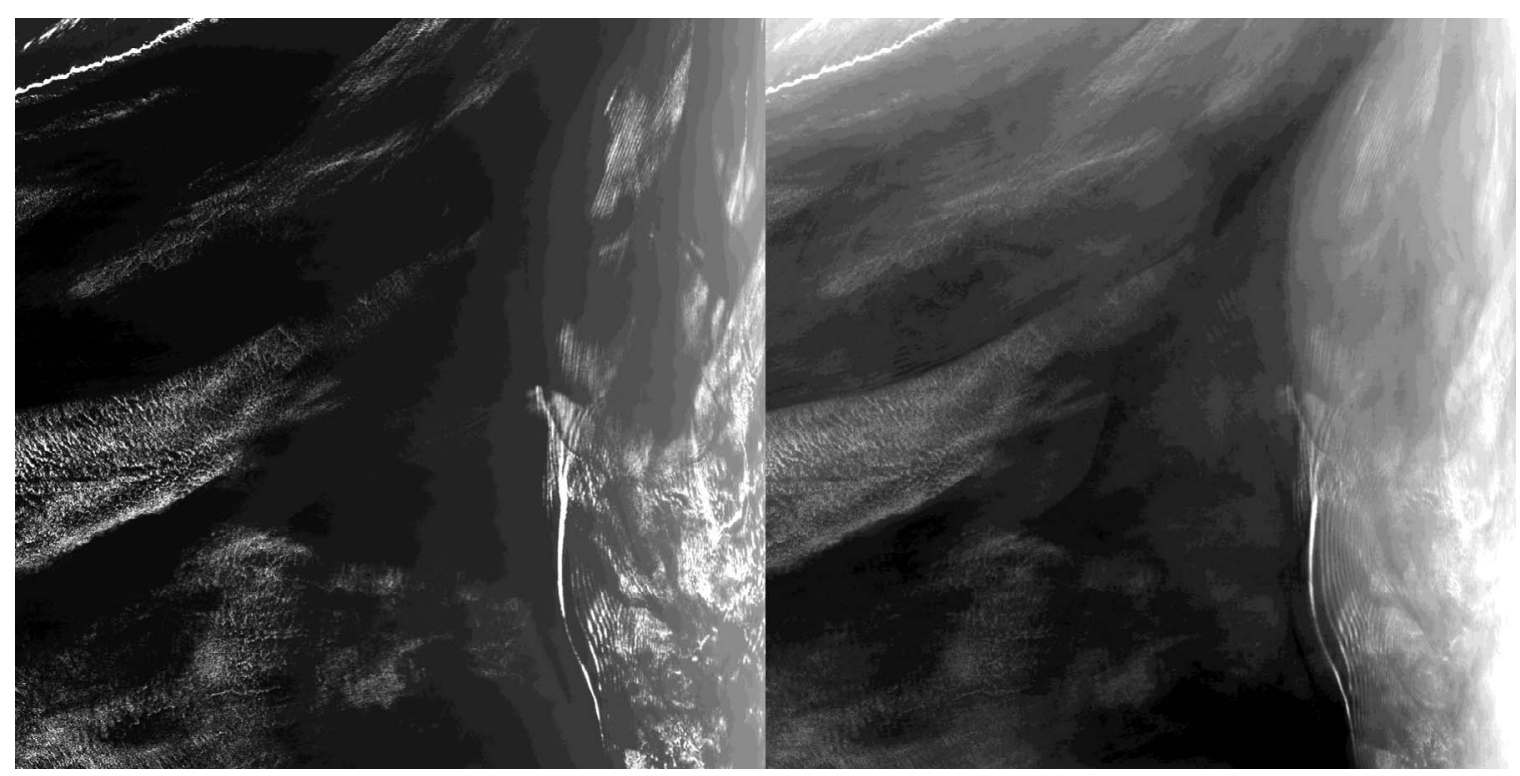

Figure 1. AVHRR images on 6 March 1999, 1105 UTC, in (left) channel 1 (VIS $0.6 \mu \mathrm{m}$ ) and (right) channel 5 (IR $12 \mu \mathrm{m}$ ), with the wave cloud pattern (right side of each image) and surrounding clouds. Note the different cloud coverage before (left side of each image) and after (right side of each image) the passage of each solitary wave.

[15] The formation process of the solitary wave cannot be determined precisely due to the absence of several satellite images during the night. Images between 0030 and 0200 IST (Meteosat slots 39 to 42) are missing at this period of the year (eclipse period of the satellite). Mechanisms leading to the formation of solitary waves will be examined in section 3.4.

[16] We have identified five phases.

[17] 1. A clearly identified, long line-shaped cloud, possibly followed by secondary parallel line clouds, becomes visible and starts to propagate westward.

[18] 2. At this time of the day (before noon), convection starts and low-level clouds (cumulus) are not present or not numerous in front of the well identified wave cloud(s). Behind the wave cloud, the passage of the wave seems to enhance convection and condensation. Clouds are more numerous than on its front side.

[19] 3. During the afternoon, convection is active and the wave cloud propagates among low-level clouds (cumulus). It becomes less well defined as time goes on, but can still be identified among the other low-level clouds.

[20] 4. Some parts of the wave clouds have a long life duration and can still be tracked during a second night and the following day. During this phase, they may cross other line clouds moving away from the Arabian peninsula (3 March case). This phase is not present or cannot be distinguished from the previous one for the waves with a short lifetime (7 March case).

[21] 5. In the last phase, dissipation, the wave cloud has lost his long line shape. The remaining presence of the wave can only be identified by a band of larger cumulus clouds indicating locally enhanced convection. At some stage, no reinforced cloud alignment can be distinguished: the wave has disappeared. This happened in the vicinity of the Arabian peninsula coast for the 3 and 4 March cases.

[22] These 5 phases correspond to a progressive transition from a solitary wave structure clearly identified by longi- tudinal clouds to a state where the presence of the wave is only detected visually by its effects on convection on fields of cumulus clouds. Approximate durations and phases are summarized in Table 1.

\subsection{Trajectory of Solitary Waves and Derived Propagation Characteristics}

[23] Solitary wave trajectories are constructed from series of images by two complementary methods derived from cloud motion vector calculation techniques [Szantai et al., 2002]. Both methods, the automatic and the manual cloud tracking methods, and the properties of the resulting trajectories and their limits are described in Appendix A.

[24] The start image that we selected is image 8 of the day (0330 UTC). At this time (corresponding to 0900 IST), the cloud line associated with the solitary wave is well-formed and easy to track. In practice, a group of trajectories is calculated for different parts of the cloud line. Figure 3 shows the trajectories of the solitary waves for the 3 and 6 March 1999 in the IR channel. On 6 March, trajectories have a long duration and show a westward and slightly divergent motion. Note also that some cloud elements related to the solitary wave of the previous day (5 March) are also present at positions located farther west. For the 3 March case, which shows several secondary line clouds behind the main line cloud, long consistent trajectories are less numerous and originate from a smaller portion of the solitary wave. In both cases, the general motion of the line clouds is basically perpendicular to the line cloud. Note also the presence of a cloud line (rope cloud) at the northwest, related to a southeasterly flow originating from the Arabian peninsula and moving southeastward (bottom of Figure 2a). The duration of the tracking derived from the trajectories with the longest lifetime is $25 \mathrm{~h}$ on 3 March and $21 \mathrm{~h} 30 \mathrm{~min}$ on 6 March. This covers the phases 2 to 4 of the solitary 
a)
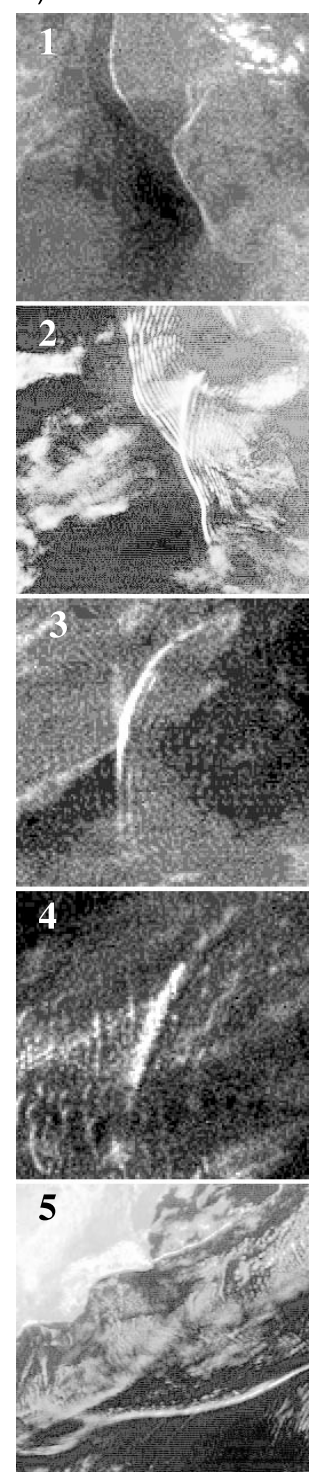

b)

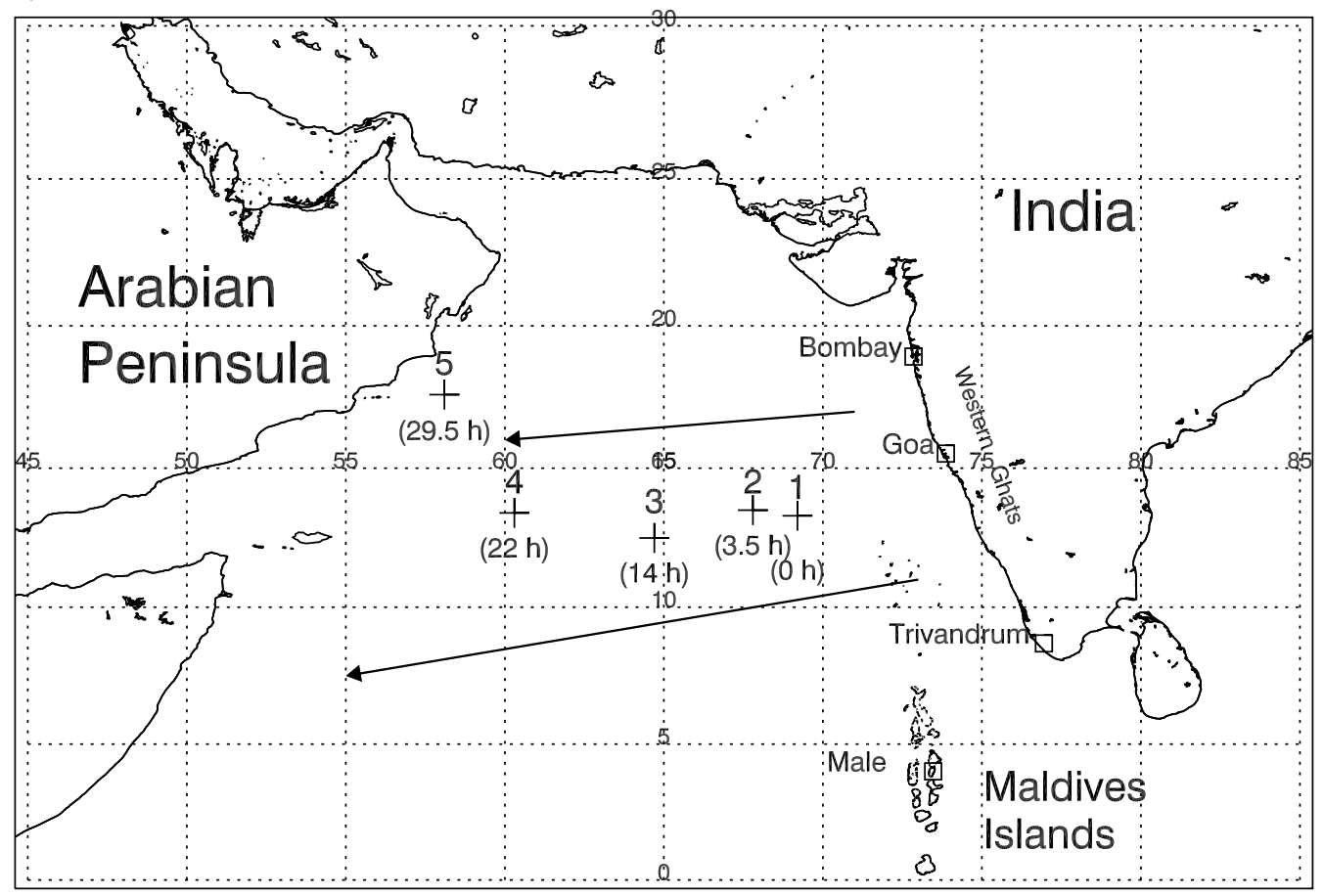

Figure 2. (a) The five stages of the life of a solitary wave, based on Meteosat satellite image observation (3 March 1999 case, with time referenced to first image, and with geographical location of image center): stage 1, presence of a continuous wave cloud (IR image); stage 2, propagation of the wave in a relatively cloud-free area (VIS); stage 3, propagation in a low-level cloud field area (IR); stage 4, propagation during the second night and the following daytime (IR); and stage 5, dissipation phase (with a southwest/ northeast oriented fuzzy line cloud) (VIS). (b) Positions of image center, and time (relative to the upper image, taken on 3 March at 0230 UTC), are also indicated on the map. Arrows give the general direction of propagation.

wave lifecycle (Table 1), when the solitary wave is well established and clearly identifiable as such.

\subsubsection{Solitary Wave Velocity}

[25] The velocity of the wave is derived from the motion vector measured in pixels between two consecutive images and the time interval between them, normally $1 / 2 \mathrm{~h}$. Figure 4 shows the solitary wave speed profile for 4 representative cases $(3,4,6$ and 7 March) of the examined period. Although some differences appear between the profiles of individual trajectories and show some variability for each wave case, common features have been observed on all cases of the 3-7 March period: (1) The propagation speed of the wave is about $10-18 \mathrm{~m} \mathrm{~s}^{-1}$. (2) During the first $24 \mathrm{~h}$, the wave speed is larger than the ambient wind at or close to the altitude where the wave clouds are located, which corresponds to low levels (950 to $850 \mathrm{hPa})$. (3) The wave accelerates within the first $24 \mathrm{~h}$ in most cases. The behavior for the 6 March (first described by DSPD2003) is a particular case: the wave first accelerates during the night of formation, then its speed is stable during daytime, and finally it accelerates again during the following evening. Whatever causes this increase in the wave speed, this similarity in behavior for all the cases can be explained at least partly by the meteorological conditions, in particular the absence of strong wind 


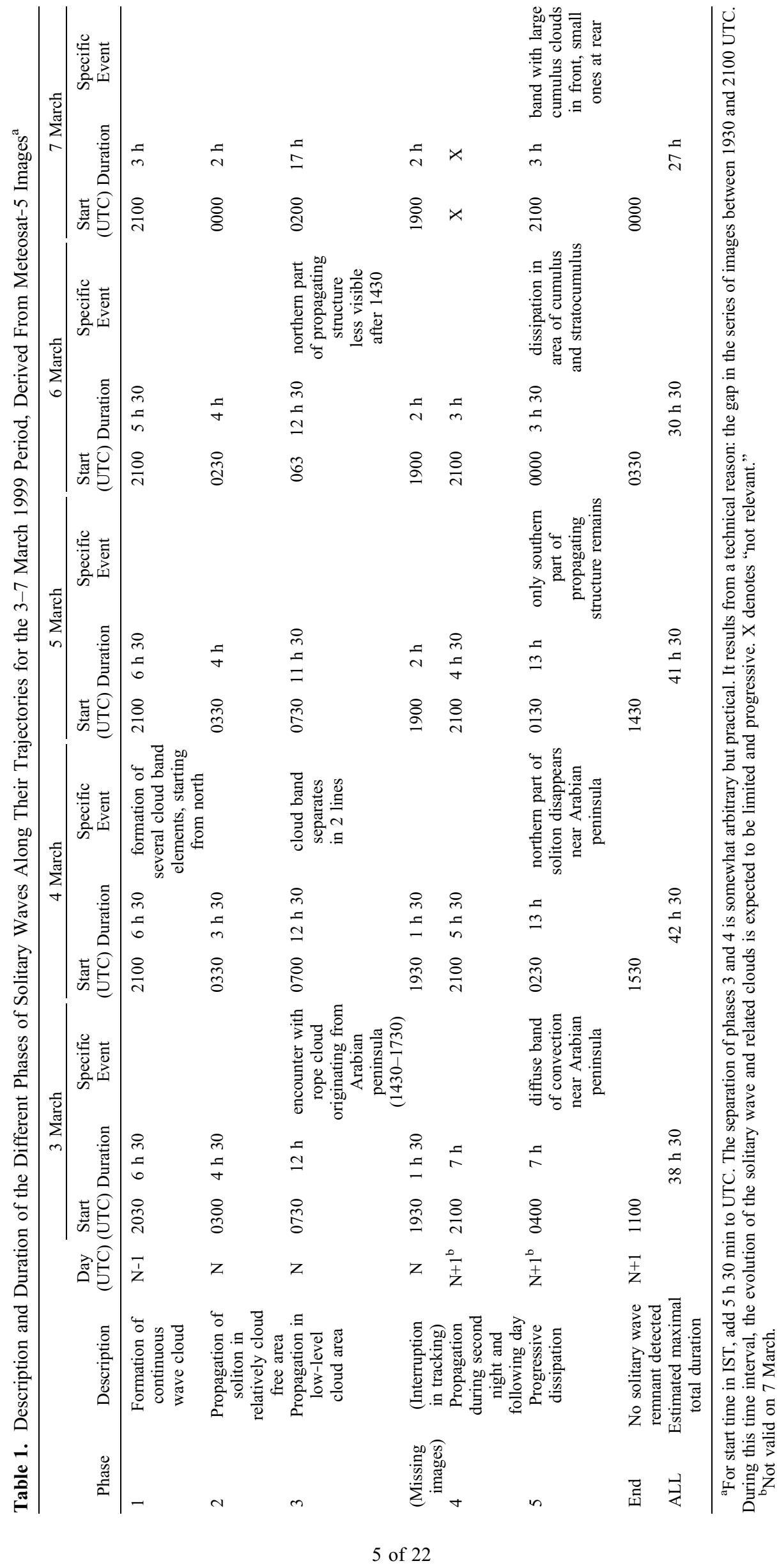


a)

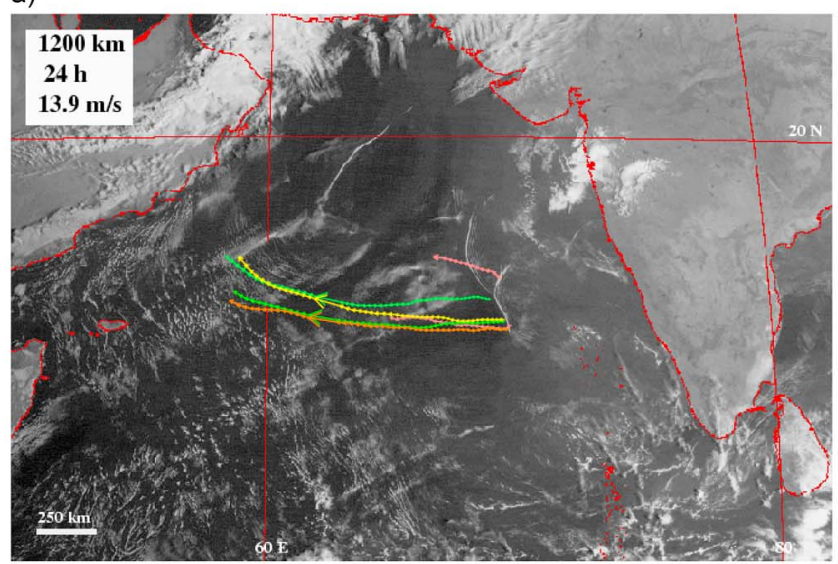

b)

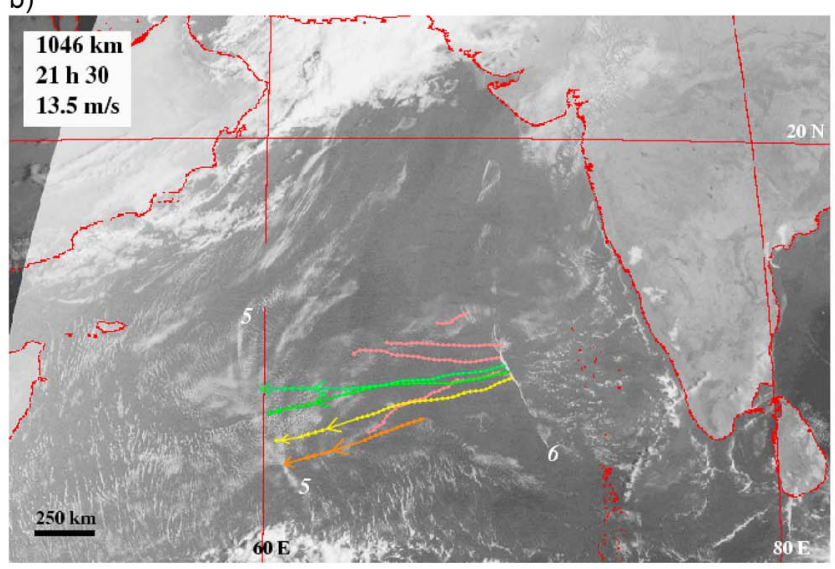

Figure 3. (a) Solitary wave trajectories for the 3 March case, IR channel, superimposed on the 3 March 1999, 0330 UTC (0900 IST) VIS image: automatically reconstructed trajectories and manually extracted direct trajectories. (b) Solitary wave trajectories for the 6 March case, IR channel, superimposed on the 6 March 1999, 0330 UTC VIS image. The southernmost trajectory starts later (at 1300 UTC) than the other trajectories (starting at 0330 UTC). The position of the solitary wave of the previous day ( 5 March) is also indicated. On top left of each image, length, duration, and average speed of the longest represented trajectory are given.

and the dominant low-cloud coverage, which were quite stable during this period. The 7 March case is more complex: the wave speed is higher for the northern part than for the southern part of the solitary wave. (The meteorological situation will be described in section 3.1.)

\subsubsection{Wave Profiles}

[26] The tracking of the solitary wave during phases 2 to 5 is based in the first place on the presence of a long, continuous, linear cloud structure. This clearly identifiable line cloud is on some images followed by one or several other parallel line clouds, which have a lower reflectance in the VIS channel or a higher brightness temperature in the IR channel. Secondary line clouds appear only if sufficient humidity is present at the level of propagation of the solitary wave (Figure 5, left). These secondary line clouds are only visible behind parts of the first (main) line cloud (Figures 1 and 3 ), and on a limited number of consecutive images.
[27] Cross sections with pixel values in the VIS channel (reflectivities) have been extracted from Meteosat images along the direction of propagation of the solitary wave, i.e., on the axis perpendicular to the direction of the line cloud, for each position along its trajectory. (Practically, 5 parallel lines of pixels have been averaged.) An undular bore structure, with a leading cloud followed by at least three less reflective cloud lines, stands out in Figure 5 (right) during the first $5 \mathrm{~h}$ (first 10 sections) along the trajectory. On the following cross sections, some peaks of reflectivity are amplified with respect to their neighbors, or are broadened due to the encounter of the solitary wave with other convective low-level clouds.

[28] The horizontal wavelength of the solitary wave corresponds approximately to the distance between two consecutive cloud lines. (The wavelength is defined by the distance, and is measured here and later between two consecutive crests of the wave.) The distances between the first, second and third cloud lines have been derived from the cross sections (Figure 6). The distance between the two first cloud lines is increasing linearly (with a regression coefficient $\mathrm{R}=0.83$ ). Between the second and third cloud lines, the increase of the distance is smaller, but this measurement is less reliable $(\mathrm{R}=0.34)$.

[29] During the tracking ( $7 \mathrm{~h} 30 \mathrm{~min})$, the horizontal wavelength derived from the distance between consecutive cloud lines, increases from about 14 to $20 \mathrm{~km}$. In particular, a distance of $14.6 \pm 1.6 \mathrm{~km}$ has been measured between the first two cloud lines at the instant of passage and location of the solitary wave above the Ron Brown (on 7 March, shortly after 0400 UTC). The distance measured between the second and third cloud lines is slightly smaller: $12.4 \mathrm{~km}$ for the same case.

\subsection{In Situ Observation of Solitary Waves From Ship and Aircraft}

[30] The Sagar Kanya research vessel navigated in the vicinity of the West Indian coast, at a distance of about $130 \mathrm{~km}$, between 5 March, 1300 UTC and 8 March 1999. From its limited measurements (no high-frequency surface pressure available), no evidence was found of the passage of solitary waves. Measurements of the Ron Brown research vessel were better documented and provided evidence of the passage of solitary waves.

\subsubsection{Detection of the Passage of Solitary Waves on Board the Ron Brown}

[31] During the examined period (3 to 7 March 1999), the Ron Brown research vessel (R.V.) was based in the Maldives islands, at Male until 5 March at 1300 UTC, when she started to navigate northward. The Ron Brown crossed the path of solitary waves on 6 and 7 March.

[32] On 6 March 1999, the Ron Brown encountered the southern part of a solitary wave between 0533 and 0540 UTC (Figure 7a). At this location, the observed clouds do not have the usual aspect of a well-defined, line-shaped cloud possibly followed by secondary wave clouds, but are in the continuation of the main cloud line located farther north. On the surface wind measurements, important changes (peaks) in speed and direction are observed at 0533 and 0538 UTC, respectively; a peak is also observed on the air temperature at 0540 UTC (Figure 8). On the other hand, no significant change has been detected on pressure measure- 
a)

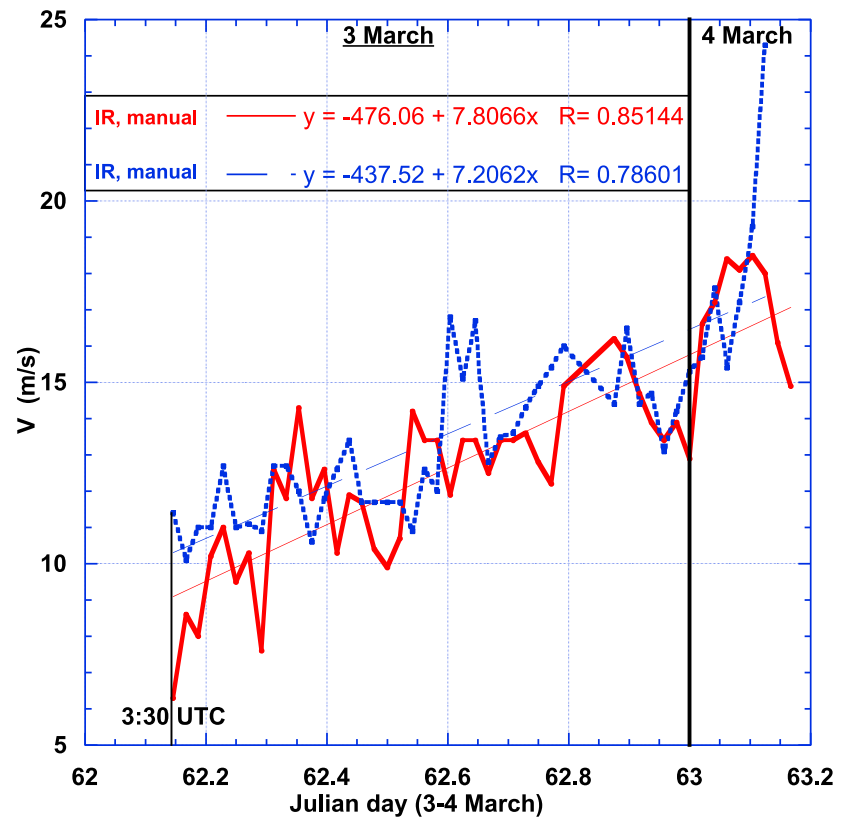

c)

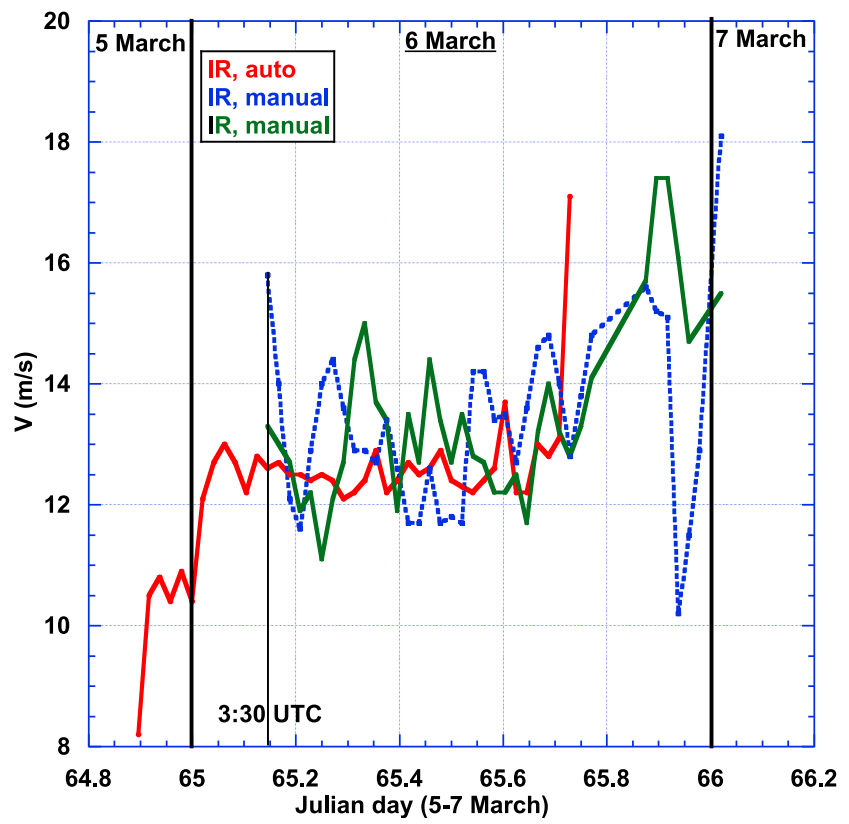

b)

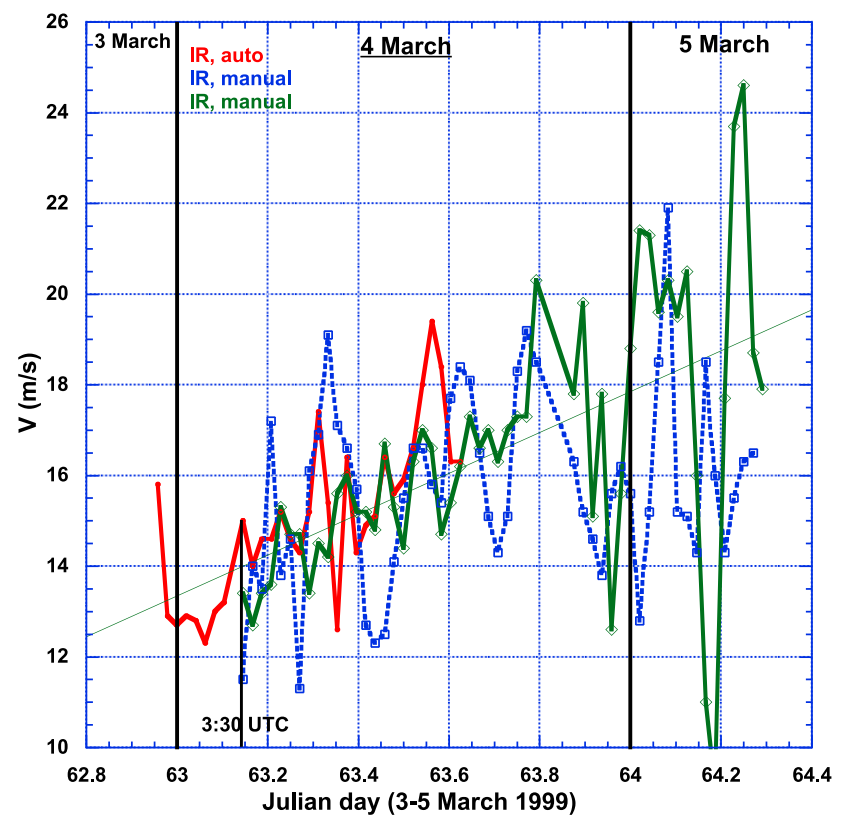

d)

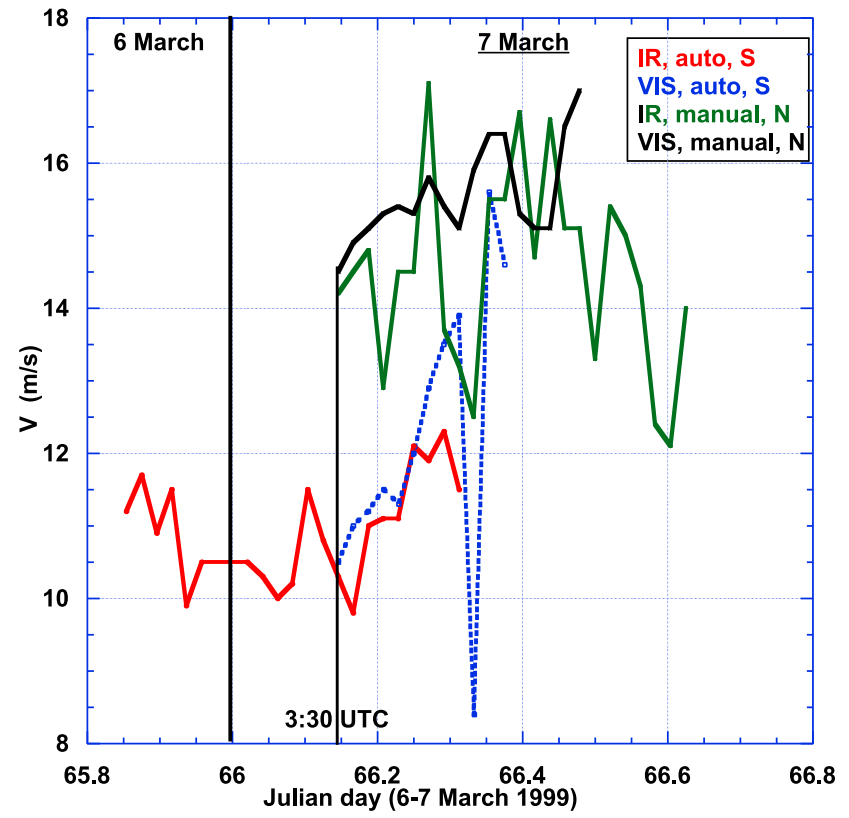

Figure 4. Solitary wave speed profiles (a) along two IR trajectories on 3 March 1999, (b) along three IR trajectories on 4 March, and (c) along three IR trajectories on 6 March, and (d) speed profiles along three IR and one VIS trajectories on 7 March 1999. Note that speeds are higher for the trajectories of the northern part $(\mathrm{N})$ of the 7 March solitary wave than for the trajectories of the southern part (S).

ments. These features likely correspond to the remains of the dissipating southern part of the solitary wave, which was present on previous satellite images.

[33] On 7 March 1999, the Ron Brown encountered a well-defined solitary wave at 0404 UTC. Figure $7 \mathrm{~b}$ shows the position of the ship shortly after the passage of the solitary wave (this part of the Meteosat image was taken around 0415 UTC). In Figure 9, the passage of the solitary wave can also be identified on measurements from the Ron Brown instruments: (1) a sharp pressure increase of about
$0.4 \mathrm{hPa}$; (2) a rapid change of the wind, with a sharp increase of about $2.5 \mathrm{~m} \mathrm{~s}^{-1}$ of the speed (later followed by a slow decrease), and an abrupt change in direction of about $30^{\circ}$ (from northwest to northeast); and (3) a deep gap in the received shortwave radiation (decrease of $270 \mathrm{~W} \mathrm{~m}^{-2}$ ), slightly delayed, followed by several peaks and gaps of smaller amplitude probably corresponding to the passage of line clouds.

[34] At least the first two gaps and peaks may well correspond to the passage of the main and a second cloud band 

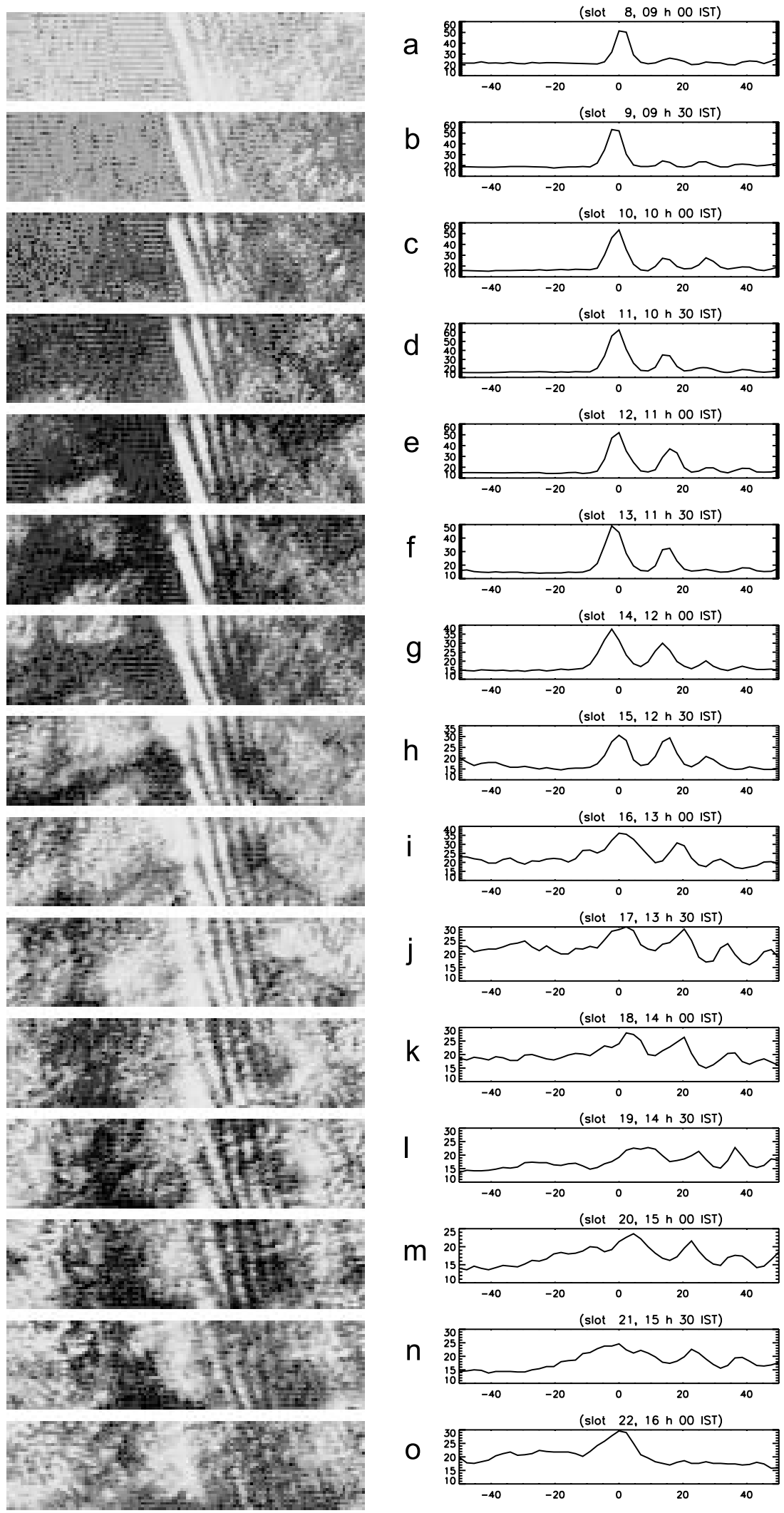

b

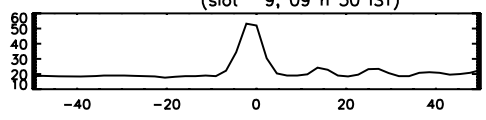

C

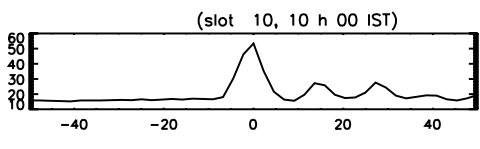

d

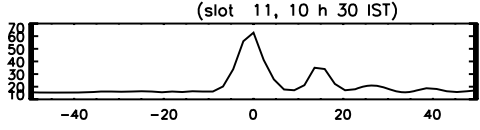

e

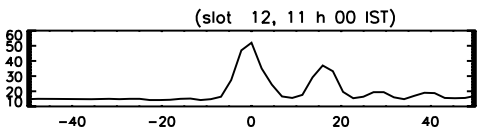

f

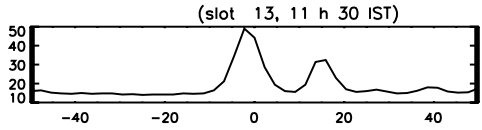

$g$

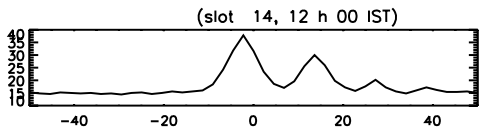

h
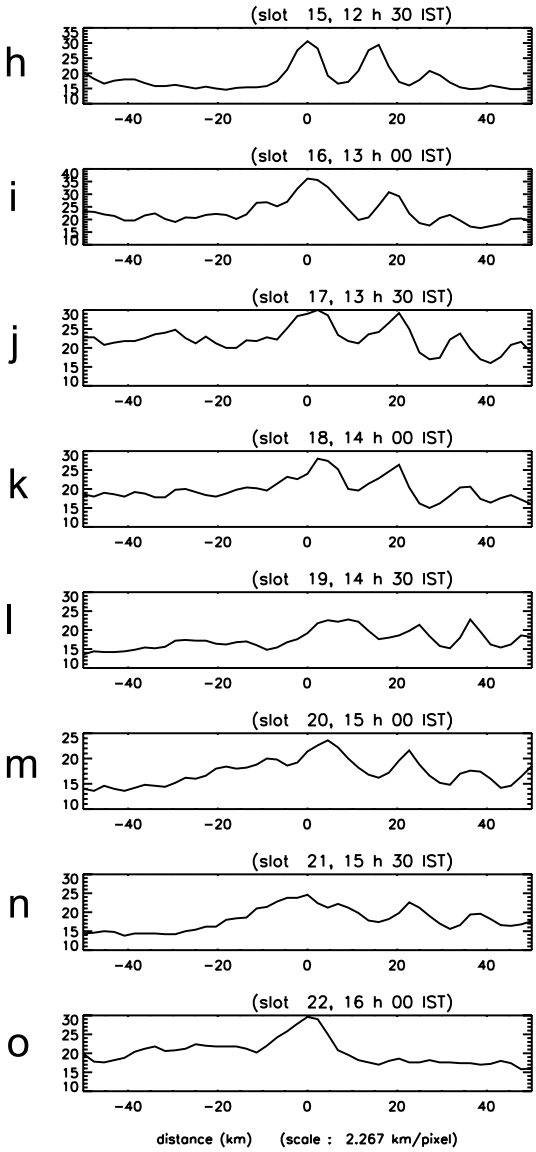

Figure 5. (left) Image elements of the solitary wave (with several consecutive cloud lines) extracted along a trajectory from a series of VIS images on 7 March 1999, 0330-1100 UTC; (right) corresponding cross sections (perpendicular to the wave clouds). The horizontal scale is in kilometers and approximately centered on the leading wave of the soliton. In the graphs for Figures 51-5o, the first peak is broadened due to the encounter of the solitary wave with another cloud. 


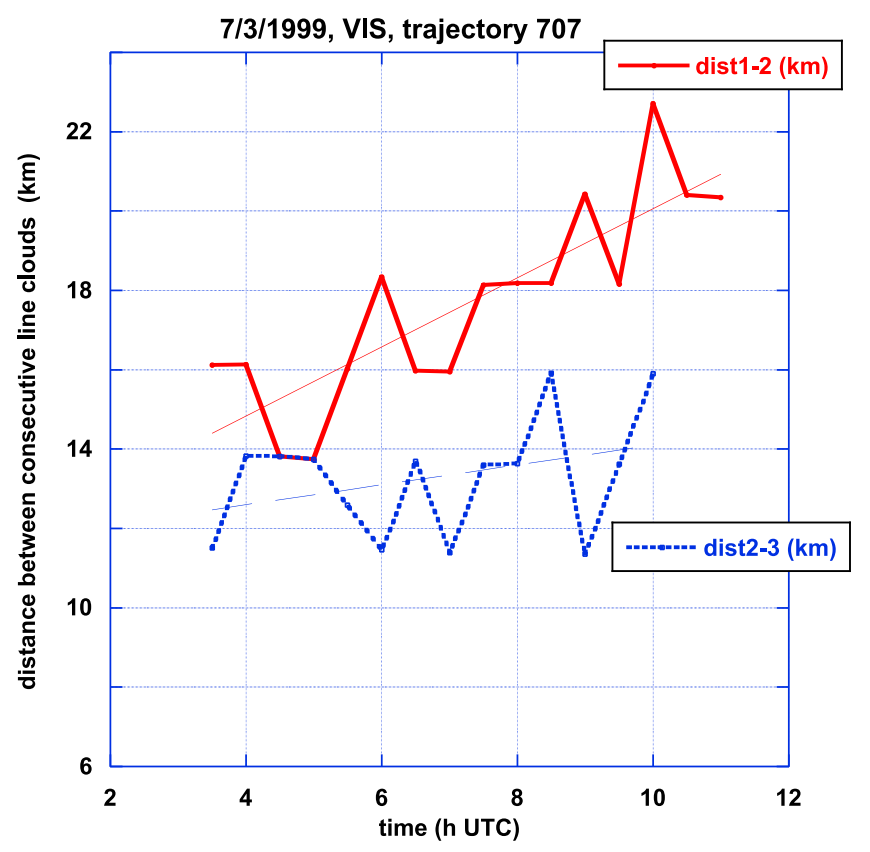

Figure 6. Distances between the first, second, and third line clouds (i.e., between local maxima of reflectivity) along the VIS trajectory shown in Figures $4 \mathrm{~d}$ and 5 (7 March 1999, 0330-1100 UTC).

above the Ron Brown. Other small clouds may also be present behind the cloud line(s), explaining some of the fluctuations on the shortwave radiation curve.

[35] The following characteristics are common features observed at the surface at the passage of morning glories: a sharp rise in wind speed, a rapid change in the wind direction, a temperature rise (possibly followed by a slower decrease) [Clarke, 1972]. Similar features have also been observed during the passage of solitary waves ahead of a density current generated under a thunderstorm [Fulton et al., 1990].

[36] For the 7 March case, the wave characteristics have been deduced from the time interval between two consecutive peaks of the pressure or the direction of the wind (12.5 min). After retrieving the velocity component of the ship along the axis of propagation of the solitary wave, and using the propagation speed measured from the satellite images $\left(\mathrm{c}=13.7 \mathrm{~m} \mathrm{~s}^{-1}\right)$, we derived its wavelength, $11.4 \mathrm{~km}$, corresponding to a period of $13.8 \mathrm{~min}$. This wavelength is close to the value determined directly from the satellite image in section $2.2(14.6 \pm 1.6 \mathrm{~km})$.

\subsubsection{Dropsonde Measurements}

[37] On 7 March 1999, the Hercules C-130 aircraft from the NSF/NCAR Research Aviation Facility made a flight over the northeast Indian Ocean. Besides measurements of meteorological surface parameters and concentration of various atmospheric components, it also served as the launch platform of 12 dropsondes. A part of its trajectory followed the $12^{\circ} \mathrm{N}$ parallel, and crossed the 7 March solitary wave almost at a right angle. The 8 last dropsondes, dropped between 0609 and 0734 UTC between $71^{\circ} \mathrm{E}$ and $64^{\circ} \mathrm{E}$ with and interval of $1^{\circ}$ of longitude (Figure $7 \mathrm{~b}$ ), measured various meteorological parameters along their descent, in particular pressure, temperature and relative humidity. These parameters will be used in section 3.2 to construct potential temperature and relative humidity cross sections ahead, above and behind the solitary wave.

\section{Lifecycle of Solitary Waves and Involved Mechanisms}

\subsection{Meteorological Conditions}

[38] As mentioned in section 1, solitary waves have been observed during 4 periods of the INDOEX experiment: (1) 15 January, (2) 16-19 February; (3) 27 February to 7 March, and (4) 1-3 April. The solitary waves of the third period have been observed under specific meteorological conditions.

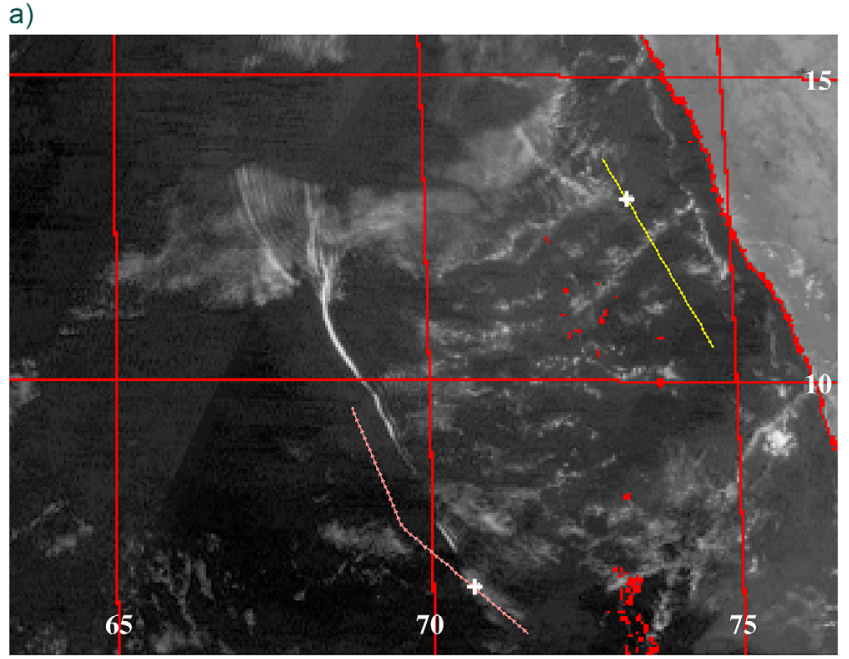
b)

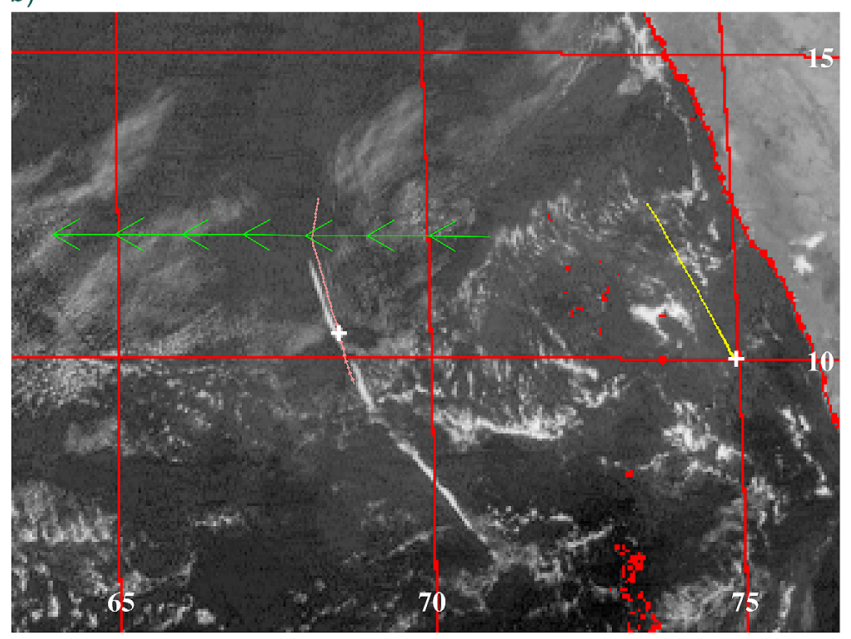

Figure 7. Position of the solitary wave at the time of its encounter with the Ron Brown research vessel (left plus sign), and corresponding Meteosat VIS image: (a) 6 March 1999, 0530 UTC (1100 IST) and (b) 7 March, 0400 UTC (0930 IST) images. The trajectories of the research vessels Ron Brown (pink) and Sagar Kanya (yellow) on the corresponding day are also indicated. Arrows along the $12^{\circ} \mathrm{N}$ parallel join the positions of dropsonde launched from the Hercules C-130 airplane, between 0609 and 0734 UTC (green) on 7 March image. 
a)
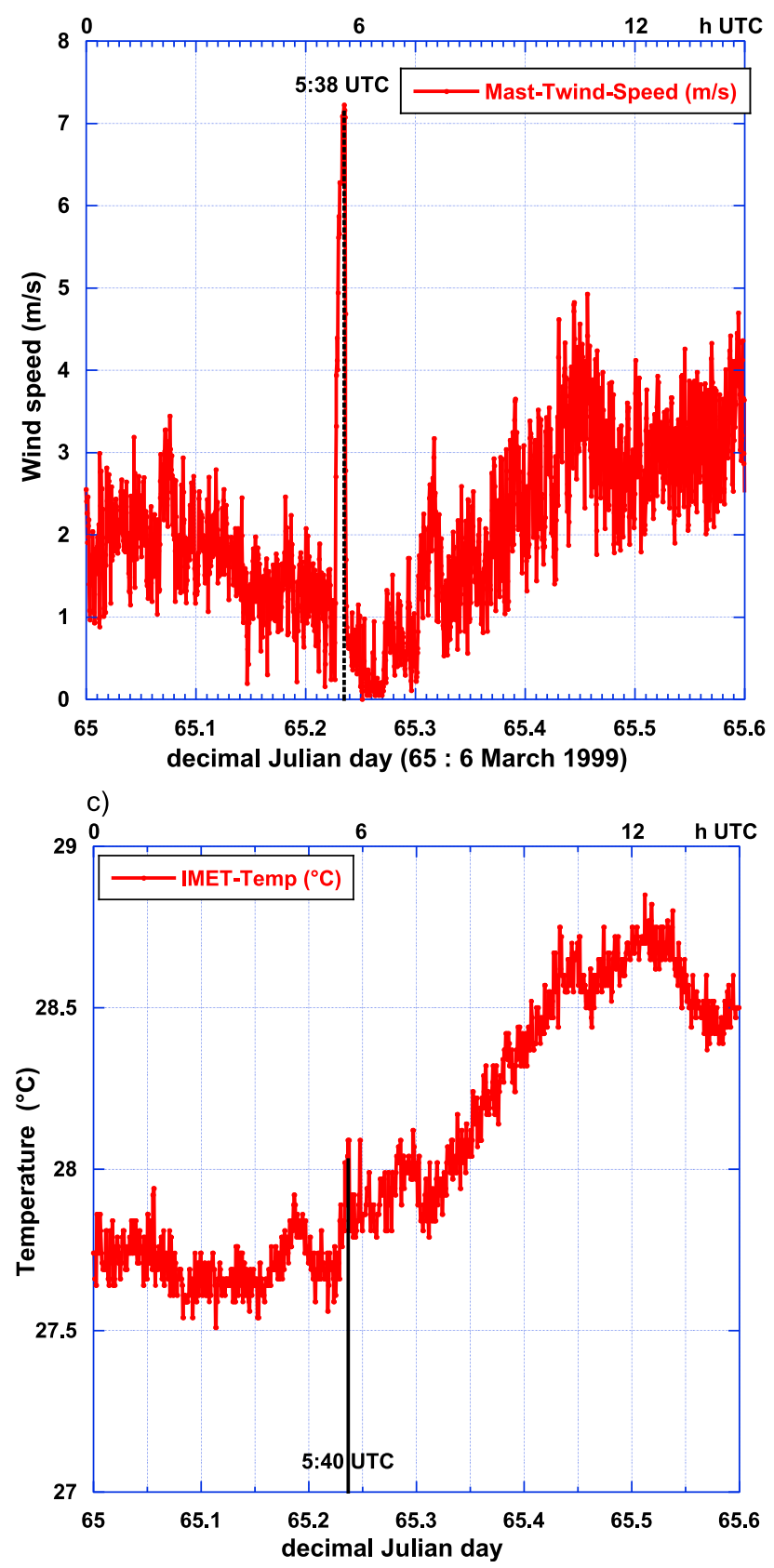

b)

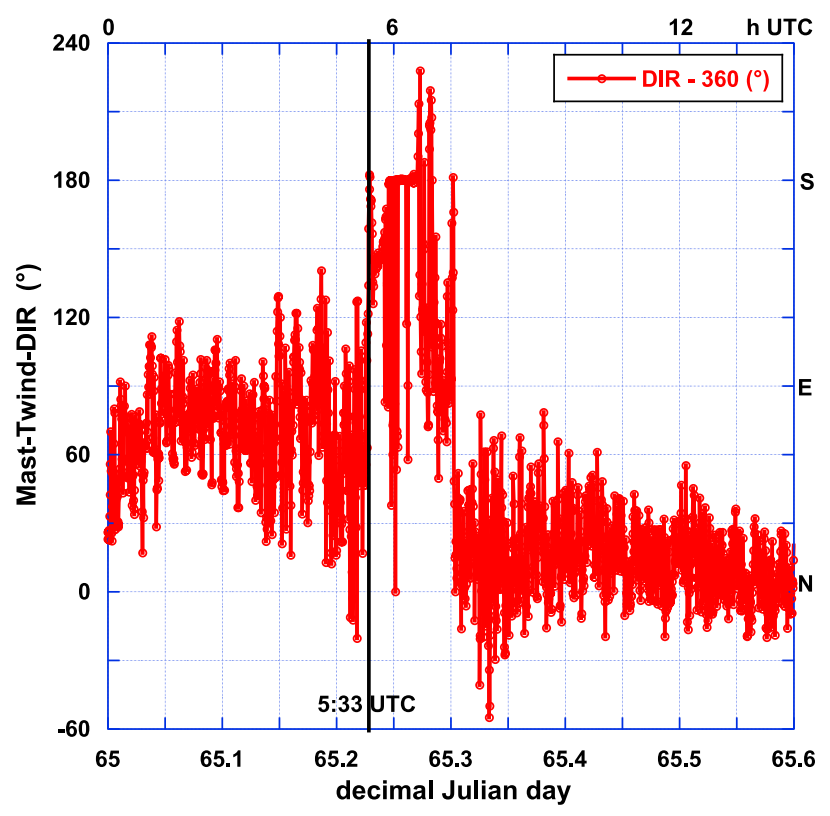

Figure 8. The 6 March 1999 case. (a) Surface wind speed measured on the Ron Brown around the time of passage of the solitary wave (0533 UTC; 1103 IST). (b) Wind direction. (c) Temperature.

[39] 1. During the INDOEX experiment, from January to March 1999, 4 main atmospheric low-level flows have been observed [Verver et al., 2001] over the northern Indian Ocean: (1) a northeasterly flow (trade winds) along the western Arabian Sea, (2) a north/northwesterly flow along the West Indian coast, (3) northeasterly trades along the East Indian coast, and (4) an easterly/northeasterly flow from southeast Asia, located at the south of the Bay of Bengal. When channel 2 was turned off or reduced, the absence or reduction of northwesterly winds in the vicinity of the West Indian coast is favorable for the presence of solitary waves: this configuration has been observed during the 27 February to 7 March period, and also during the 16-19 February period. An active channel 2 is related to the motion of barocline disturbances from Pakistan to the north of India. On the other hand, changes in the activation of channels 2 and 3 are related to the position of the northern tropical convergence zone, located farther south during the 27 February to 7 March period; this position is dependent on the phase of the Madden-Julian oscillation.

[40] 2. The presence of sea and land breezes. Sea breezes can be observed almost every day during February and March. Dekate [1968] noted that sea breezes over Bombay were present 29.5 days in average in March, and 22 days in February during the 1961-1964 period. They start typically at 1100-1200 IST (0530-0630 UTC), and have a duration 
a)

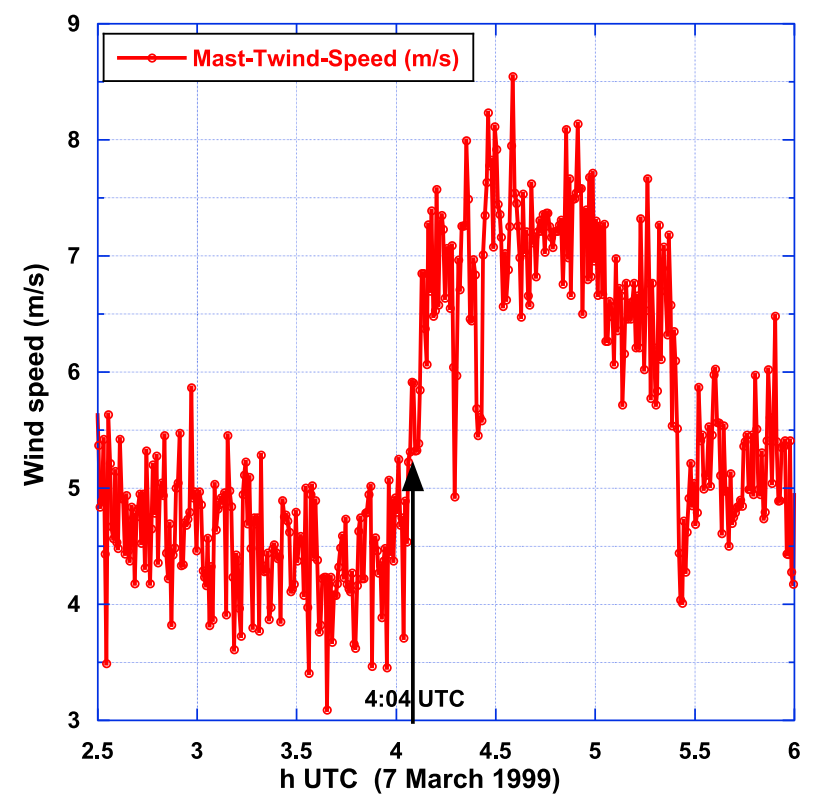

c)

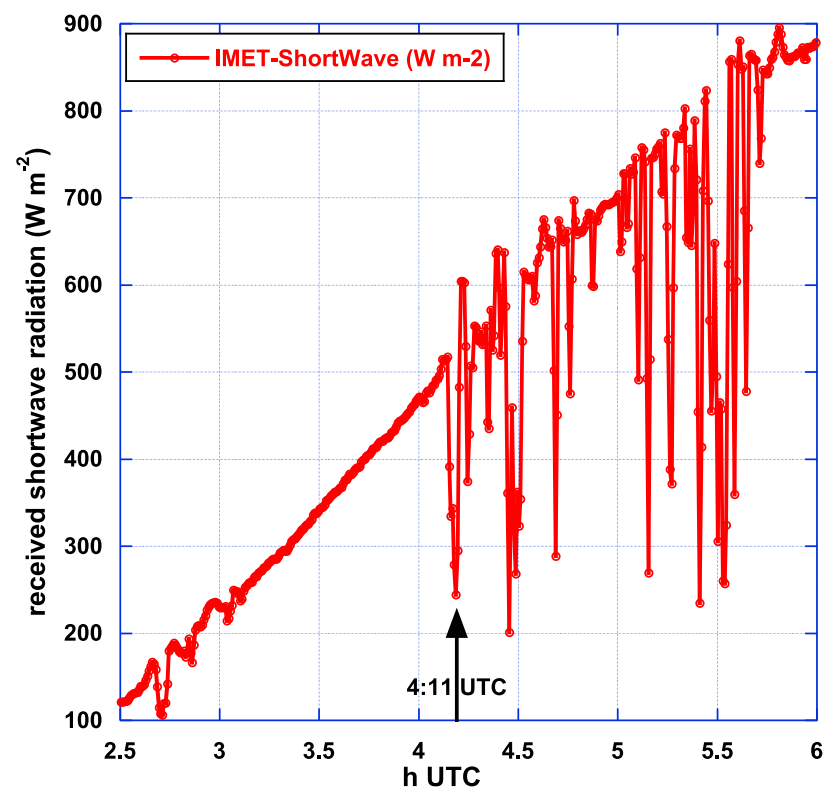

b)

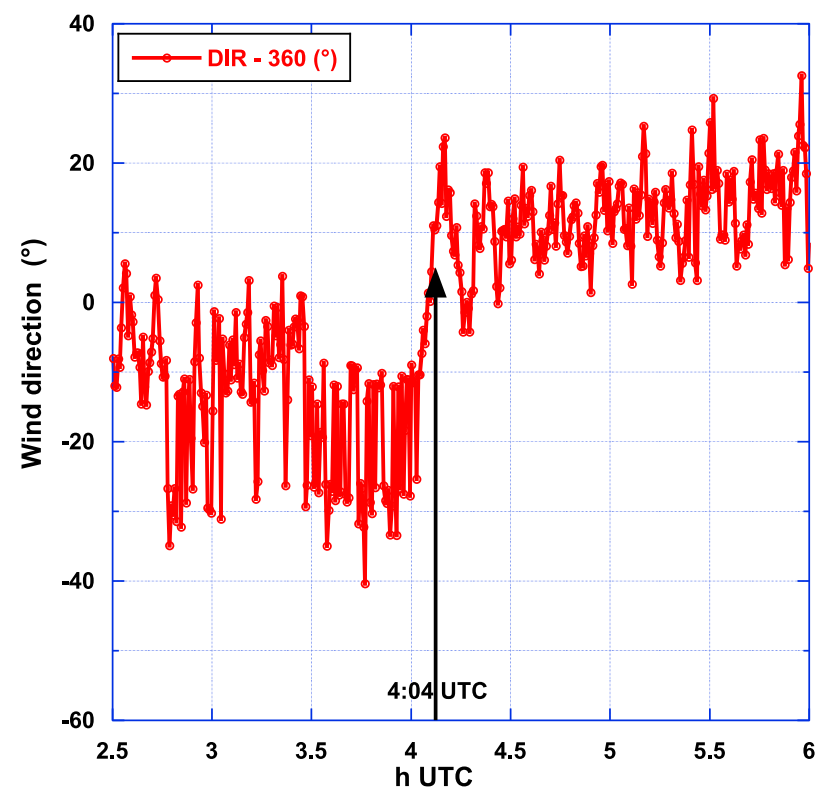

d)

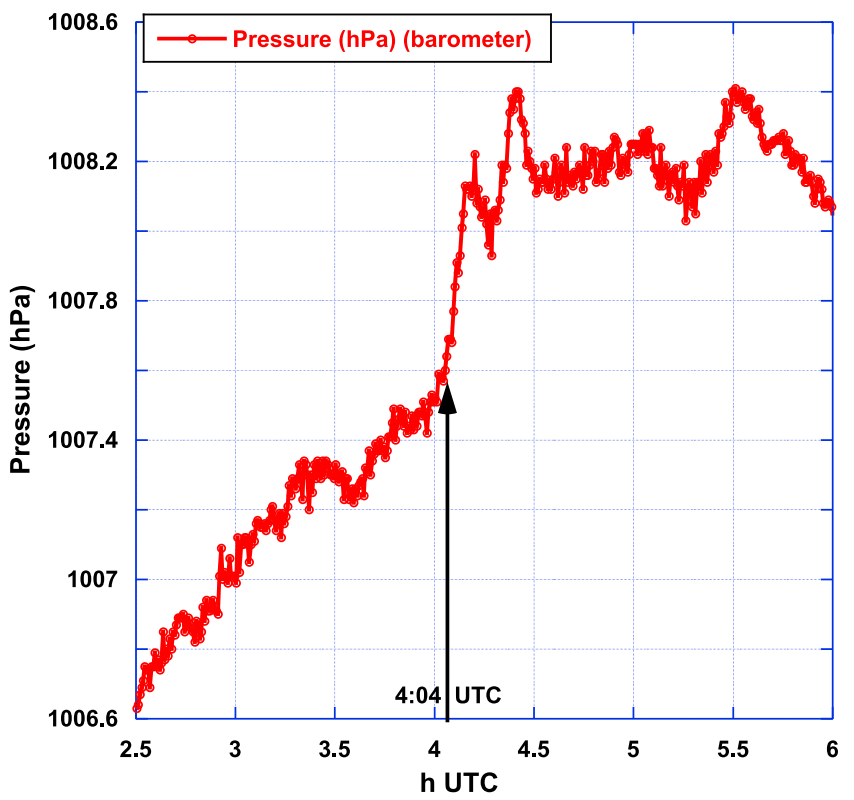

Figure 9. The 7 March 1999 case. (a) Wind speed measured on the Ron Brown around the time of passage of the solitary wave (0404 UTC; 0934 IST). (b) Wind direction. (c) Received shortwave radiation. (d) Surface pressure.

of $9 \mathrm{~h}$ to $10 \mathrm{~h} 30 \mathrm{~min}$ in March. Land breezes are weak, typically 1-3 $\mathrm{m} \mathrm{s}^{-1}$, they are less frequent than sea breezes (22 days in average in March and 20.5 in February), and have an onset at 0300-0500 IST (2130-2330 UTC) in March (earlier in February). The presence of the sea breeze has been observed by stations in Trivandrum (Thiruvananthapuram) and Goa between 4 and 9 March 1999 [Subrahamanyam et al., 2001], and in Bombay. The wind speed was small, close to $4 \mathrm{~m} \mathrm{~s}^{-1}$. On the other hand, the presence of a land breeze is less obvious, with weak wind speeds, close to 0 . Wind measurements on board the Sagar Kanya during her journey parallel to the West Indian coast (5-7 March) at a distance of approximately $130 \mathrm{~km}$ have shown that the sea breeze (and all the more the land breeze) did not reach the ship, thus giving a limit to its extension. As indicated in sections 3.4 and 3.5 , breezes may play a role in the generation of solitary waves.

[41] 3. Important quantities of continental aerosols, including pollutants, have been advected from the Indian subcontinent over the Arabian Sea. This phenomenon has been observed in particular in the northwest of India in Goa and Dharwar during the INDOEX experiment [Leon et al., 
a)

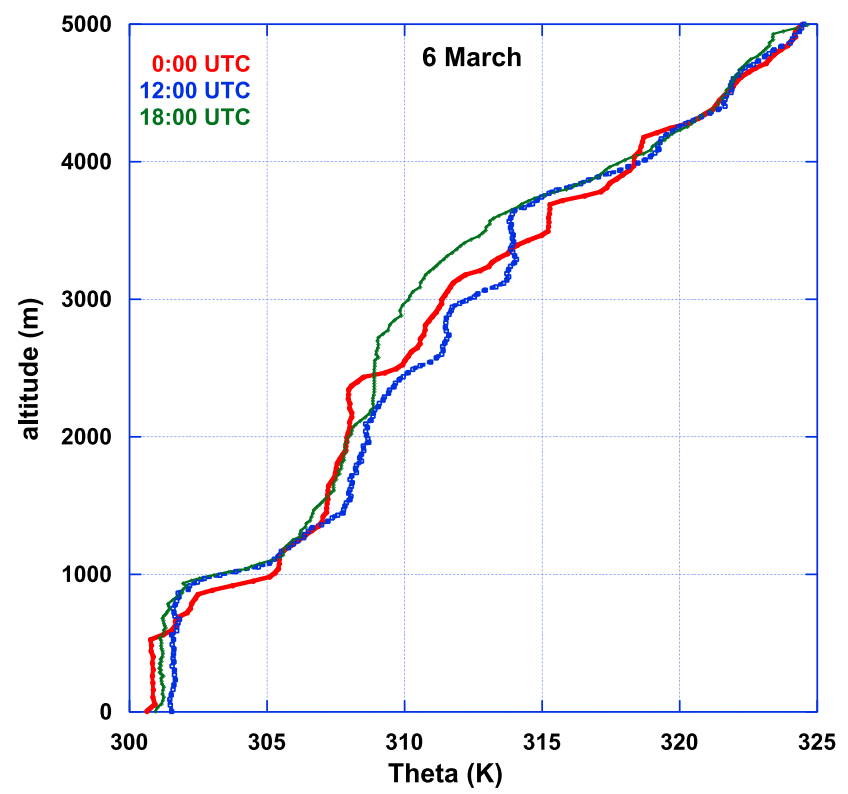

c) b)

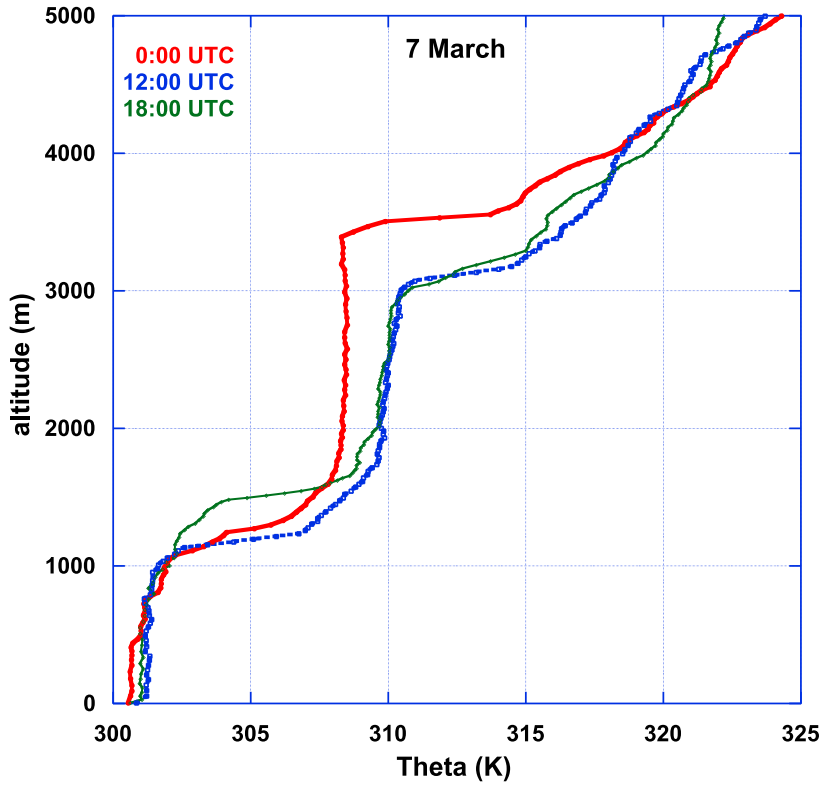

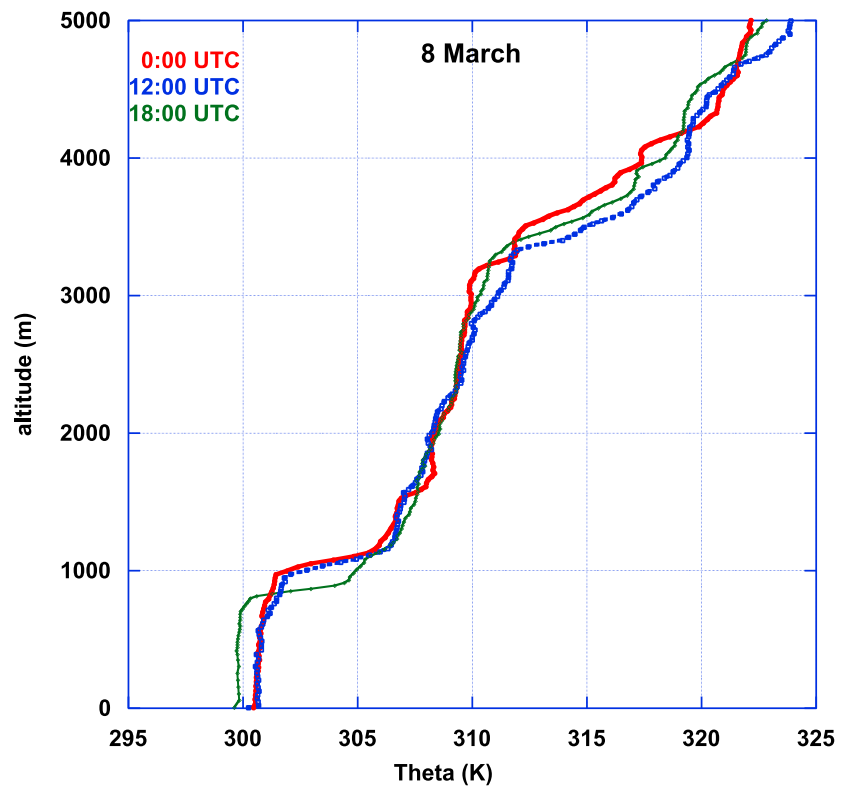

Figure 10. Potential temperature (in $\mathrm{K}$ ) derived from radiosondes launched from the Ron Brown on (a) 6, (b) 7, and (c) 8 March 1999.

2001]. Advected aerosols flow above sea/land breeze cells in the West Indian coastal area, and form a separate layer and a flow above the marine boundary layer. These two layers have clearly different characteristics: distinct potential temperatures and ozone concentrations have been measured on board the Ron Brown and Sagar Kanya ships [Simpson and Raman, 2004], and confirmed by the airborne lidar from the Mystere 20. On 7 March, the marine boundary layer reached a height of 700-1000 $\mathrm{m}$ above the sea, and the land plume was located between 1000 and $3000 \mathrm{~m}$. As explained in section 3.2, the presence and stability characteristics of these layers may play an important role on the existence and propagation of the solitary waves.
[42] These meteorological elements are characteristic of the third observation period. Note that some of them, in particular sea breezes, were also observed during periods when no solitary waves were observed.

\subsection{Onset and Propagation Conditions of Solitary Waves}

[43] In this section we examine the environment at a local scale necessary for the formation and persistence of the observed solitary waves. Figure 10 shows the potential temperature derived from the radiosondes launched from the Ron Brown on 6, 7 and 8 March. The existence of a waveguide is suggested by the following elements: (1) One element is the presence of a relatively well-mixed neutral 

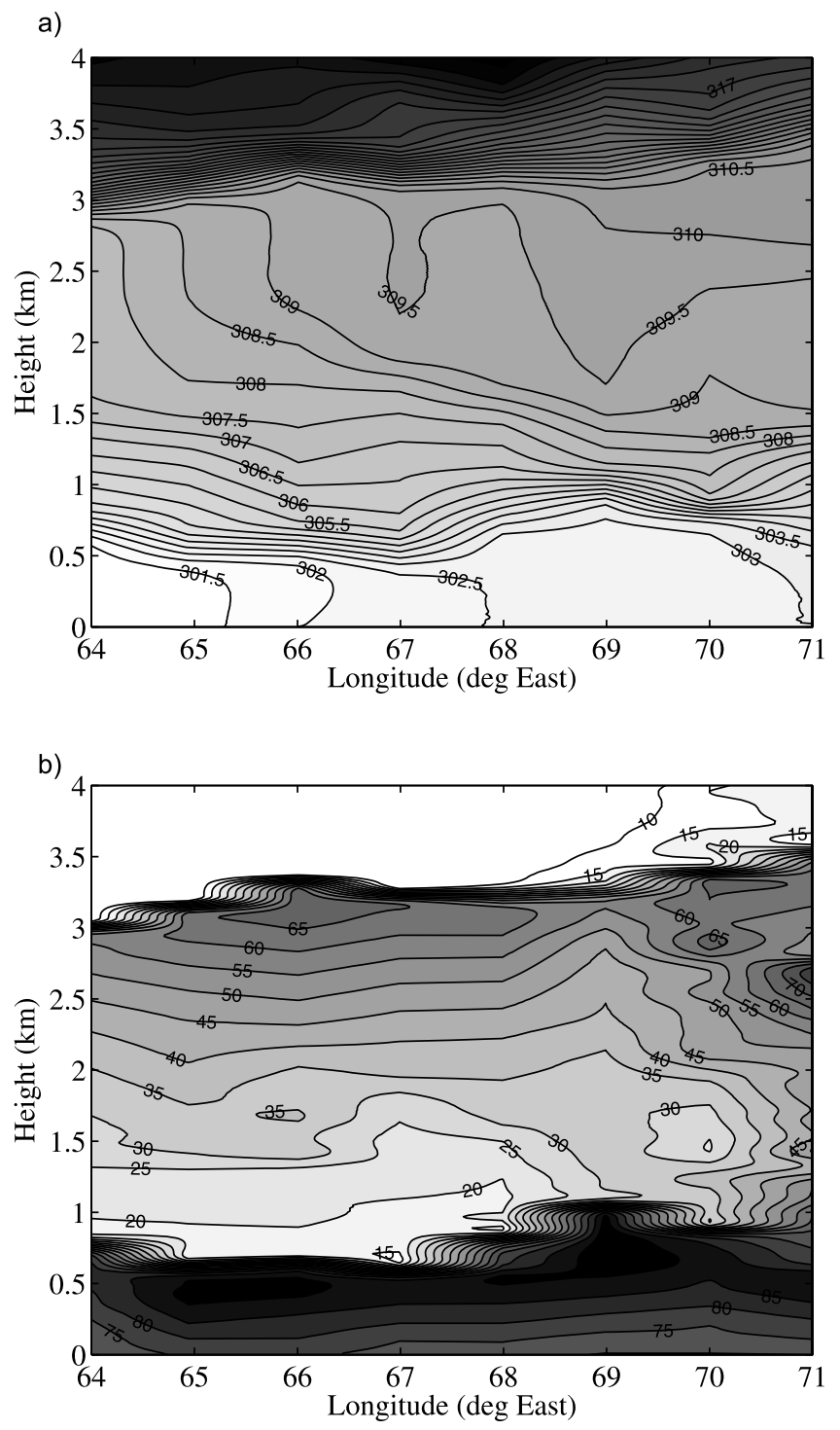

Figure 11. (a) Virtual potential temperature and (b) relative humidity on 7 March 1999 derived from dropsondes launched from the Hercules C130 airplane at constant latitude $\left(12^{\circ} \mathrm{N}\right)$.

layer, located between 1200 and $3500 \mathrm{~m}$ approximately. It corresponds to the land plume originating from the Indian subcontinent. (2) Another element is the presence of a stratified layer below this neutral layer, at a height of approximately $1 \mathrm{~km}$, where the solitary wave propagates horizontally. It is an inversion layer which is at the top of the marine boundary layer. The line clouds associated with the solitary wave and the other cumulus clouds (when present) have their base at this level. (3) A third element is the presence of a capping inversion at the top of the land plume layer. It is located between 3000 and $3500 \mathrm{~m}$ and may avoid energy dissipation of the solitary waves in the upper troposphere.

[44] The neutral layer is not as well mixed on 5 March as on the 6 and 7 March; when the Ron Brown left Male in the Maldives islands (on 5, around 1330 UTC) she was located farther south of the area where a solitary wave was observed on that day. Individual potential temperature profiles are also different between days with and without solitary waves (Figure 10c): on 8 March, the potential temperature is increasing with height in the land plume layer, indicating that it is not as well mixed as on 7 March. Note also that the 7 March 0000 UTC radiosonde exhibits a negative gradient on the virtual potential temperature in the land plume layer, indicating instability of the air mass: on Meteosat images taken a little later, this corresponds to the presence of a convective cloud, which later dissipates. Similar profiles of potential temperature showing a planetary boundary layer composed of two separated, (relatively) well-mixed sublayers have also been derived from Sagar Kanya measurements around 1000 UTC [Subrahamanyam et al., 2003]. Note that this double-layered structure was also detected farther away from the West Indian coast, during the return leg of her journey along the $15^{\circ} \mathrm{N}$ parallel, between 2 and 5 March.

[45] The examination of dropsonde data helped us to define the structure of the waveguide. Eight dropsondes have been launched between 0609 and 0734 UTC along the part of the Hercules C130 aircraft trajectory that follows the $12^{\circ} \mathrm{N}$ parallel almost perpendicularly to the solitary wave. Cross sections of virtual potential temperature and relative humidity have been derived from these dropsonde measurements. They confirm the presence of the two layers (with stable potential temperature values) and the presence of the two stratified inversion layers (with rapid variations of potential temperature with height) observed in Figure 3a of Forêt et al. [2006]). Note that the previously described layers of the lower troposphere can clearly be identified, although the trajectory of the airplane $\left(\right.$ at $\left.12^{\circ} \mathrm{N}\right)$ is north of the area where the solitary wave is observed on Meteosat images (between $6^{\circ} \mathrm{N}$ and $11.5^{\circ} \mathrm{N}$ ). The potential temperature and relative humidity profiles (Figure 11) also indicate the approximate location of the propagating wave (around $69^{\circ} \mathrm{E}$ ) and that the marine boundary layer is thicker after the passage of the wave (east of $69^{\circ} \mathrm{E}$ ). The relative humidity cross section also confirms the presence of drier air in the land plume layer ahead of the wave that had been noticed on Meteosat and AVHRR images (Figures 1 and 3).

[46] Our first hypothesis was to consider the whole land plume as the waveguide. In order to verify it, we derived the Brunt-Väisälä frequency $\mathrm{N}^{2}$, which is an indicator of the static stability of the atmosphere (Figure 12a). Between the two peaks corresponding to the strongly stratified inversion layers at approximately 700 and $3000 \mathrm{~m}, \mathrm{~N}^{2}$ has values close to zero, indicating that the layer is well mixed, except in its lower part, at a height between 900 and $1500 \mathrm{~m}$, where $\mathrm{N}^{2}$ has higher values, but far below the peak values. Note that this configuration, a lower inversion layer, a mixed layer and an upper inversion layer, can be observed on all dropsonde profiles with some variations on height before, during and after the passage of the solitary wave.

[47] Another element that can play a role in the efficiency of the waveguide is the wind profile. The presence of wind shear, of opposing flows at the level of the lower and the upper stratified layers may improve the propagation of solitary waves. Although such waves are intrinsically nonlinear, Crook [1986, 1988] determined some propagation characteristics using linear theory in a similar context, the propagation of Australian morning glories. 

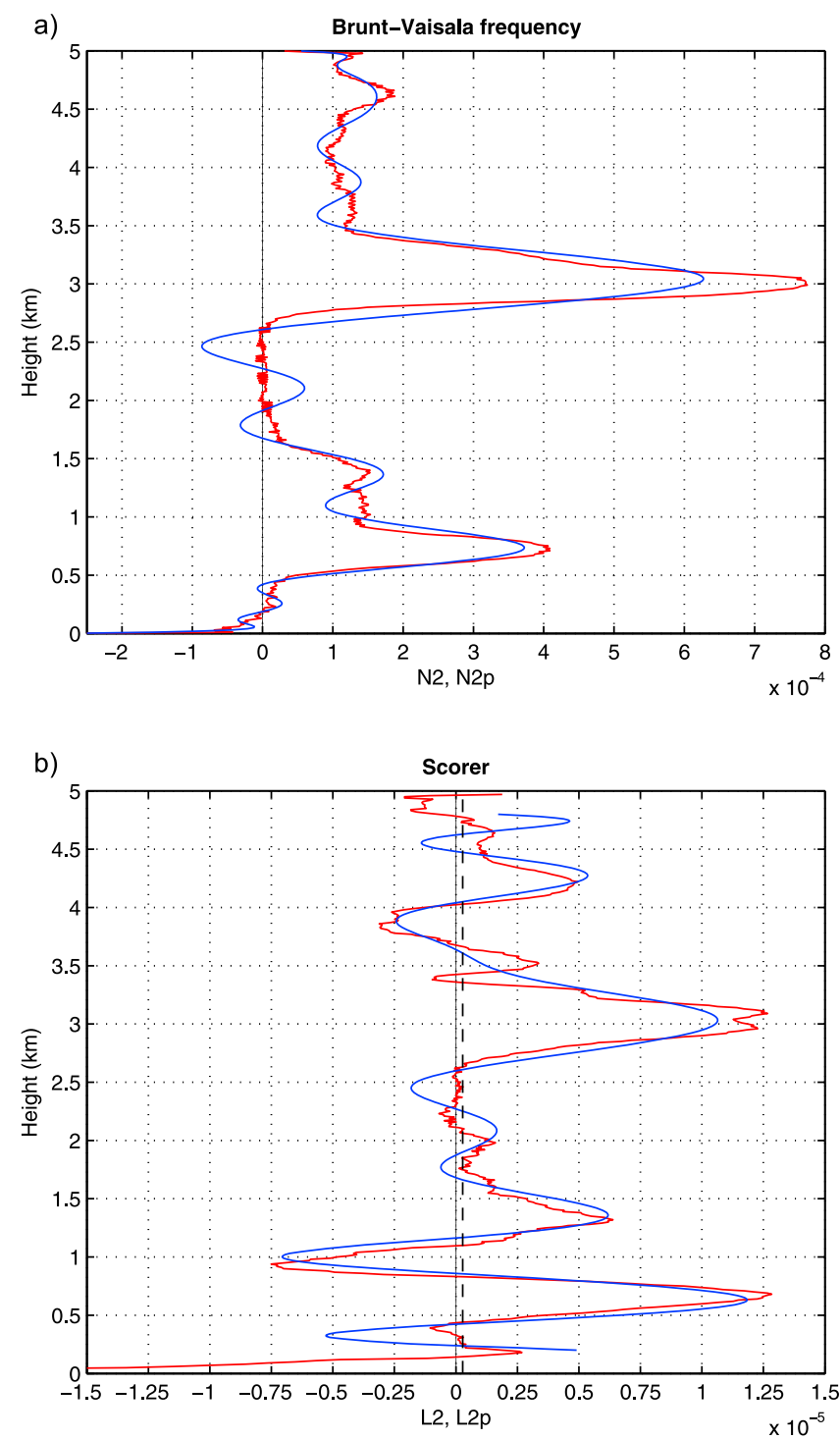

Figure 12. (a) Brunt-Väisälä frequency $\left(\mathrm{N}^{2}\right.$, in $\left.\mathrm{s}^{-2}\right)$, and (b) Scorer parameter $\left(\mathrm{L}^{2}\right.$, in $\left.\mathrm{m}^{-2}\right)$ for the last Hercules C130 dropsonde (7 March, 0734 UTC), ahead of the solitary wave. The dashed line corresponds to the wave number associated with the horizontal wavelength.

[48] If we have a linear two-dimensional wave propagating in a stably stratified atmosphere, with a horizontal wavelength $\lambda_{\mathrm{h}}=2 \pi / \mathrm{k}$ and a vertical wavelength $2 \pi / \mathrm{m}(\mathrm{k}$ and $\mathrm{m}$ being the corresponding wave numbers), the vertical velocity $\mathrm{w}$ will be governed by the Taylor-Goldstein equation:

$$
\frac{d^{2} w}{d z^{2}}+\boldsymbol{m}^{2} w=0
$$

where: $\boldsymbol{m}^{2}=\boldsymbol{l}^{2}-\boldsymbol{k}^{2}$, with $1^{2}$, the Scorer parameter (variable with height) [Scorer, 1949],

$$
l^{2}=\frac{N^{2}}{(U-c)^{2}}-\frac{U_{z z}}{U-c},
$$

with $\mathrm{N}^{2}$ : the Brunt-Väisälä frequency, $\mathrm{U}$ the wind component along the axis of propagation of the wave, $U_{\mathrm{zz}}=\mathrm{d}^{2} \mathrm{U} / \mathrm{dz} \mathrm{z}^{2}$ its second derivative with respect to height and $\mathrm{c}$ the horizontal wave speed. The value of $\mathrm{c}(=13.7 \mathrm{~m} / \mathrm{s})$ has been derived from solitary wave positions along their trajectory on satellite images. Upward propagation of the wave is inhibited when $\mathrm{m}^{2}$ is negative, i.e., when $\mathrm{l}^{2}<\mathrm{k}^{2}$. A trapped wave requires the dual condition that $\mathrm{m}^{2}>0$ at low levels (propagating wave), and $\mathrm{m}^{2}<0$ at higher levels in order to suppress the vertical radiation of energy. In the particular case where $\mathrm{N}^{2}$ is equal to 0 (well-mixed layer) and in the absence of vertical wind shear $\left(\mathrm{U}_{\mathrm{zz}}=0\right)$, no vertical propagation of the wave is possible.

[49] The measured wind may undergo rapid fluctuations during the descent of dropsondes, thus leading to important fluctuations of its second derivative (and thus on its component $U_{z z}$ along the solitary wave propagation direction). In order to reduce these fluctuations, $\mathrm{U}_{\mathrm{zz}}$ and also $\mathrm{N}^{2}$ have been smoothed. The Scorer parameter $1^{2}$ (calculated for all the dropsondes along the $12^{\circ} \mathrm{N}$ parallel) is particularly significant for the vertical propagation of waves before the passage of the solitary wave (i.e., corresponding to last 3 dropsondes launched between 0709 and 0734 UTC). Figure $12 \mathrm{~b}$ shows the Scorer parameter for the 0734 UTC dropsonde, which has been dropped at the greatest distance ahead of the solitary wave. The level where the solitary wave can propagate horizontally is in the lower stratified layer, around $700 \mathrm{~m}$, which also corresponds to a peak of the Brunt-Väisälä frequency. The layer where the solitary wave can propagate vertically is located at a height of approximately $700 \mathrm{~m}$ that corresponds to a peak of the Scorer parameter (with $1^{2}>0$ ). This layer is surrounded by two layers with a negative Scorer parameter, above between 850 and $1100 \mathrm{~m}$, and below between 400 and $300 \mathrm{~m}$, which inhibit vertical wave propagation. This structure of a large, positive peak of the Scorer parameter at a height between 500 and $1000 \mathrm{~m}$, located between a deep minimum with a negative Scorer parameter above, and a second, less important minimum with a negative or zero value below, can be observed on most dropsonde profiles along the $12^{\circ} \mathrm{N}$ parallel. Although these dropsonde profiles only cover a small part of the area of the Indian Ocean where solitary waves propagate, this indicates that favorable conditions are present over a large area (between 64 and $71^{\circ} \mathrm{E}$, this corresponds approximately to $750 \mathrm{~km}$ ) for horizontal wave propagation without important energy loss.

[50] Note that these characteristics of the solitary wave, and others, may evolve during their lifetime. As mentioned in section 2, their speed increases or may remain stable during daytime in some cases, the horizontal wavelength increases slightly, the first cloud line remains alone in the last stages and becomes broader and attenuated. But it is beyond the scope of this article to investigate the physical conditions which enable and explain such a long persistence of the solitary waves.

\subsection{Mathematical Reconstruction of Solitary Waves}

[51] In section 2 we determined some of the properties of the solitary waves from the cloud pattern on images: (1) their horizontal wavelength, around $12 \mathrm{~km}$, is increasing with time (Figure 5 and 6); (2) the horizontal wavelength is decreasing toward the rear of the propagating 


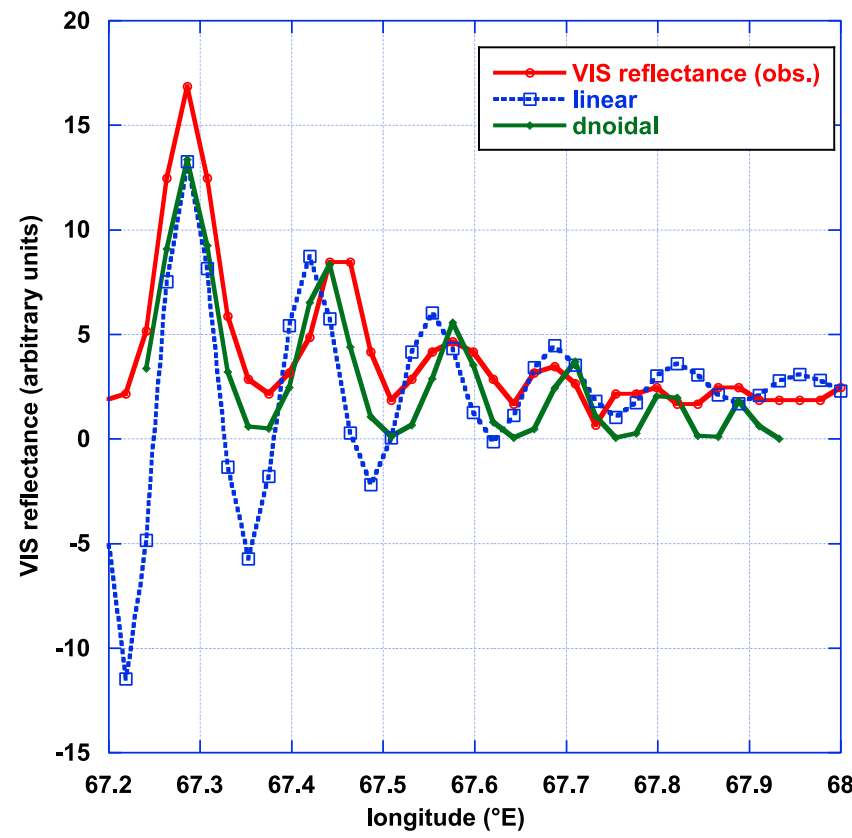

Figure 13. Observed wave profile (6 March 1999, in the VIS channel) in comparison to a profile derived from a linear (Taylor-Goldstein) equation and a profile derived from a nonlinear $(\mathrm{KdV})$ equation (dnoidal solution).

wave; and (3) the amplitude of the peaks of the solitary wave is decreasing.

[52] It is beyond the scope of this study to model completely the propagation (and formation) of the observed solitary waves. We nevertheless used equations from wave theories to reconstruct profiles compatible with observed wave profiles (Figure 13):

[53] 1. A simple modeling is based on a linear system of equations, namely the Taylor-Goldstein wave equation and the continuity equation, enables the determination of the profiles of the vertical and horizontal velocity components ( $\mathrm{w}$ and $\mathrm{u}$ ). This approach has been used by Zheng et al. [1998b] to model coastal lee waves resulting from the interaction of land breeze with opposing wind. The modeled profile show an oscillating and decreasing wave amplitude, qualitatively resembling to the observed profile of our study, but with constant distance between consecutive peaks.

[54] 2. A more realistic modeling of solitary wave patterns can be obtained with the use of a weakly nonlinear equation. The most commonly used representations are based on the Benjamin-Davis-Ono (BDO) equation and on the Korteweg-De Vries (KdV) equation [Egger, 1984; Christie, 1989; Rottman and Einaudi, 1993], which correspond to different boundary conditions. Zheng et al. [1998a] found that one of the solution to the $\mathrm{KdV}$ equation, the dnoidal solution, fits approximately to the wave profile they observed over the northern Indian Ocean. Figure 5 of Zheng et al. [1998a] shows that "the model describes the general trend of variation of observed wave amplitudes quite well, though not perfectly. One of the possible reasons to cause the departure of observations from the model may be the nonuniformity of distribution of moisture." On the other hand, the distance between observed consecutive peaks fits with the calculated variable wavelength.

[55] With a variable (decreasing) horizontal wavelength (see Figure 6 of this study), the observed wave pattern has a profile compatible with a dnoidal one, as described above. A complete modeling, which involves a correct definition of the different scale parameters, would also have to reconstruct the temporal evolution of the solitary wave along its trajectory, in particular the increase of wavelength with time and the evolution of the solitary wave.

\subsection{Formation of Solitary Waves}

[56] Solitary waves have a clearly identifiable structure on Meteosat images, made visible by line clouds, at 0330 UTC of the current day, and their presence and motion can be at best traced back to 2100 UTC of the previous day. Going back into time, in order to determine the instant and location of their formation proved to be more difficult.

[57] Our initial hypothesis was to suppose that the solitary wave was generated on or in the vicinity of the West Indian coast by some mechanism, such as a sea or land breeze. If we suppose that the solitary wave moves at a constant speed and if we take the first measured speed, we can compute its trajectory backward on its shortest way to the coast and determine at what time it would have left this coastal point. The following example presents the results of trajectory extrapolations for a point located on the northern part of the 7 March solitary wave at 0330 UTC (0900 IST) at a latitude of $\sim 11^{\circ} \mathrm{N}$, with a constant propagation speed of $15 \mathrm{~m} \mathrm{~s}^{-1}$ (based on the measured speed of individual trajectories): (1) The solitary wave has to start on 6 March at 1400 UTC (1930 IST) and takes $13 \mathrm{~h} 30 \mathrm{~min}$ to cover the $730 \mathrm{~km}$ to reach the reference point at 0330 UTC. (2) The start time from a point $80 \mathrm{~km}$ inland is 1230 UTC (1800 IST), in order to cover the $810 \mathrm{~km}$ to the reference point. (3) For an accelerating solitary wave, from a speed of $12.5 \mathrm{~m} \mathrm{~s}^{-1}$ on the coast up to a speed of $15 \mathrm{~m} \mathrm{~s}^{-1}$ at the reference point at 0330 UTC, the wave leaves at 1245 UTC (1815 IST) and travels during $14 \mathrm{~h} 45 \mathrm{~min}$ (covered distance of $730 \mathrm{~km}$ ). The acceleration value $\left(4.7 \times 10^{-5} \mathrm{~m} \mathrm{~s}^{-2}\right)$ is realistic, and close to average values measured for solitary waves observed on other days and at other periods of their lifecycle.

[58] Note that these starting instants correspond to the period of the day when the sea breeze is active and the corresponding positions would be located inside the fully developed sea breeze cell. (The periods of active breezes are based on average measurements in Bombay from Dekate [1968] and may vary a little each day and on other coastal locations.) The hypothesis of a solitary wave propagation at a speed close to the last measured values is compatible with its presence and possibly its formation in the area where the sea breeze is active. A generation of the solitary wave by the land breeze is not realistic, unless a powerful mechanism is introduced to slow down the wave. To give an order of magnitude, a solitary wave leaving the coast at 0000 UTC (0530 IST), during the time when the land breeze is expected to be present, would have to travel at a speed of $54 \mathrm{~m} \mathrm{~s}^{-1}$ during $3 \mathrm{~h} 30$ to reach the reference point at 0330 UTC.

[59] Although the trajectory of the solitary wave cannot be traced back prior to the gap in the series of images, i.e., before 1900 UTC, a few backward trajectories starting before that instant could be calculated. Rather than showing 


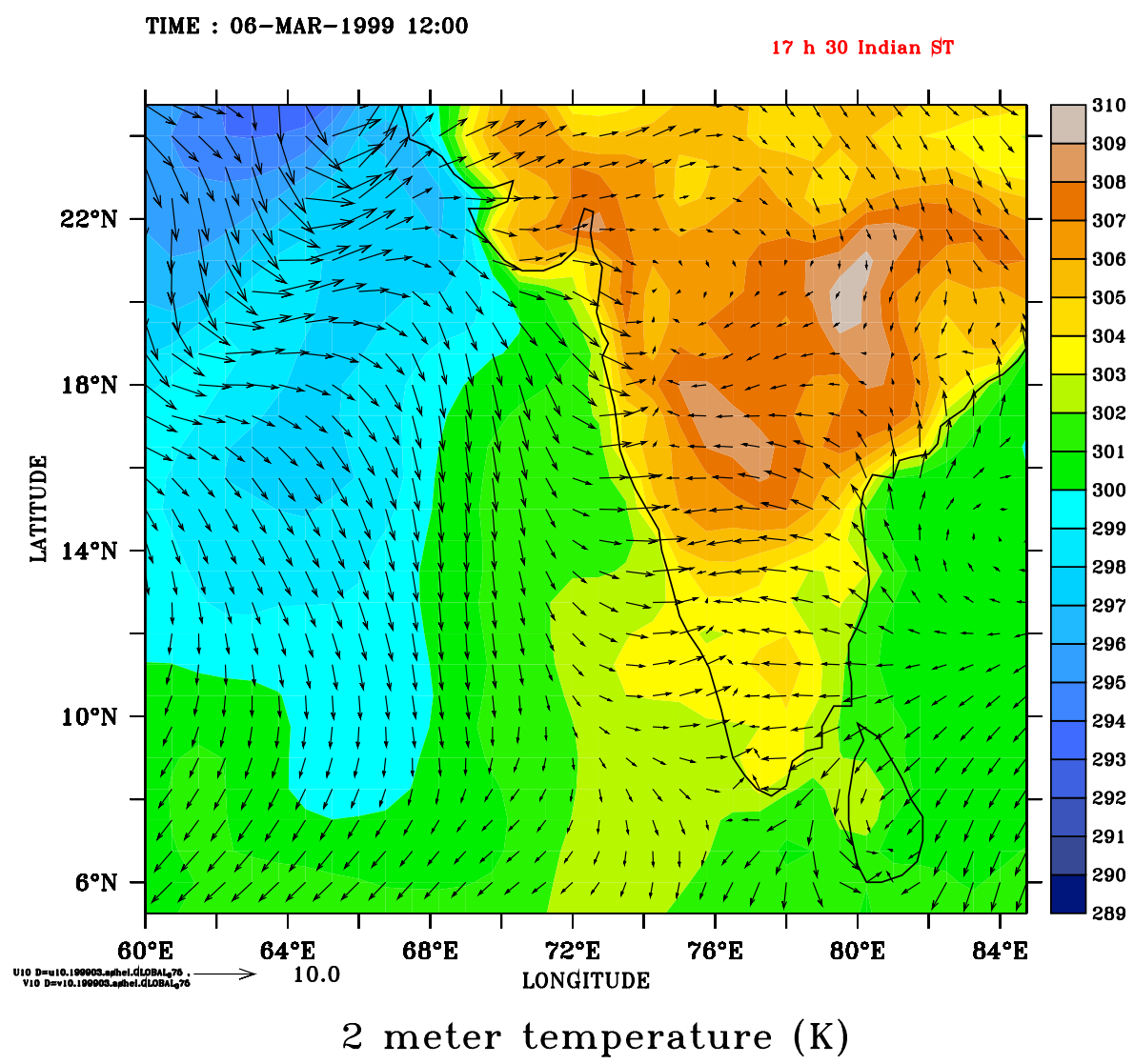

Figure 14. ERA Interim near-surface temperature (at $2 \mathrm{~m}$ ) and wind (at $10 \mathrm{~m}$ ) on 6 March 1999, 1200 UTC. Note the aligned near-zero winds parallel to the West Indian coast.

the motion of individual clouds, some of them track the edge of the cloud layer formed by smaller clouds, located between the 0330 UTC reference position of the solitary wave and the West Indian coast. Elements of this edge move at speeds between 11 and $17 \mathrm{~m} \mathrm{~s}^{-1}$, values larger than the local wind speed but close to the values measured at the 0330 UTC reference position $\left(15 \mathrm{~m} \mathrm{~s}^{-1}\right)$ for the solitary wave. This propagating edge of a cloudy area may be the signature of the solitary wave before it gets its well-defined line cloud shape and whose passage could favor convection. This cloud-edge motion speed is compatible with a generation by a sea breeze related mechanism, which will be described in section 3.5.

[60] The best explanation for the formation of the observed solitary waves is a collision of two flows of opposite directions at low levels during daytime, namely: (1) the sea breeze, with a southwesterly component, advances inland; its most advanced extension is materialized by a front, the sea breeze front; and (2) the dominant winter monsoon, which blows over the Indian subcontinent from the east/northeast.

[61] Collisions of fronts associated with opposing flows have been observed during laboratory experiments in water tanks [Simpson, 1994]. During such collisions, the lighter fluid flows above the denser one; in some cases, bores can form ahead of each reformed front.

[62] Surface ECMWF analyzed winds from the ERAInterim data set at 12:00 UTC show the convergence line where the two flows meet; this line runs approximately parallel to the West Indian coast (Figure 14).

[63] The flow of less dense, warmer air that has been heated during its passage over land encounters the flow of denser air cooled by the breeze circulation over the ocean and passes above it. In Figure 15, the horizontal wind component along the direction of propagation of solitary waves, (northeast to southwest, with a direction of $65^{\circ}$ from north), which is approximately perpendicular to the West Indian coast, is associated with the vertical wind. It shows the energetic encounter of both flows above the surface and the resulting vertical air motion. Note also the previously mentioned presence of the two layers over the ocean, the marine boundary layer and the land plume layer, separated by a thin layer with a strong stratification, around $900 \mathrm{hPa}$, and capped by a second stratified layer around $650 \mathrm{hPa}$.

[64] The exact instant of the collision between the sea breeze and the winter monsoon-related flow cannot be determined from the available data. The intensity of the sea breeze flow may be enhanced by orography: the heating by the Sun of the western slopes of the Western Ghats range, which runs parallel to the seashore at a distance of about $50 \mathrm{~km}$ and has a height of $700 \mathrm{~m}$ (locally with some elevations above $2000 \mathrm{~m}$ ), may produce thermally driven winds that reinforce the strength of the breeze circulation.

[65] A mechanism suggested for the formation of morning glories, the collision of two sea breeze fronts moving in opposite directions, is less realistic than a simple intrusion of 


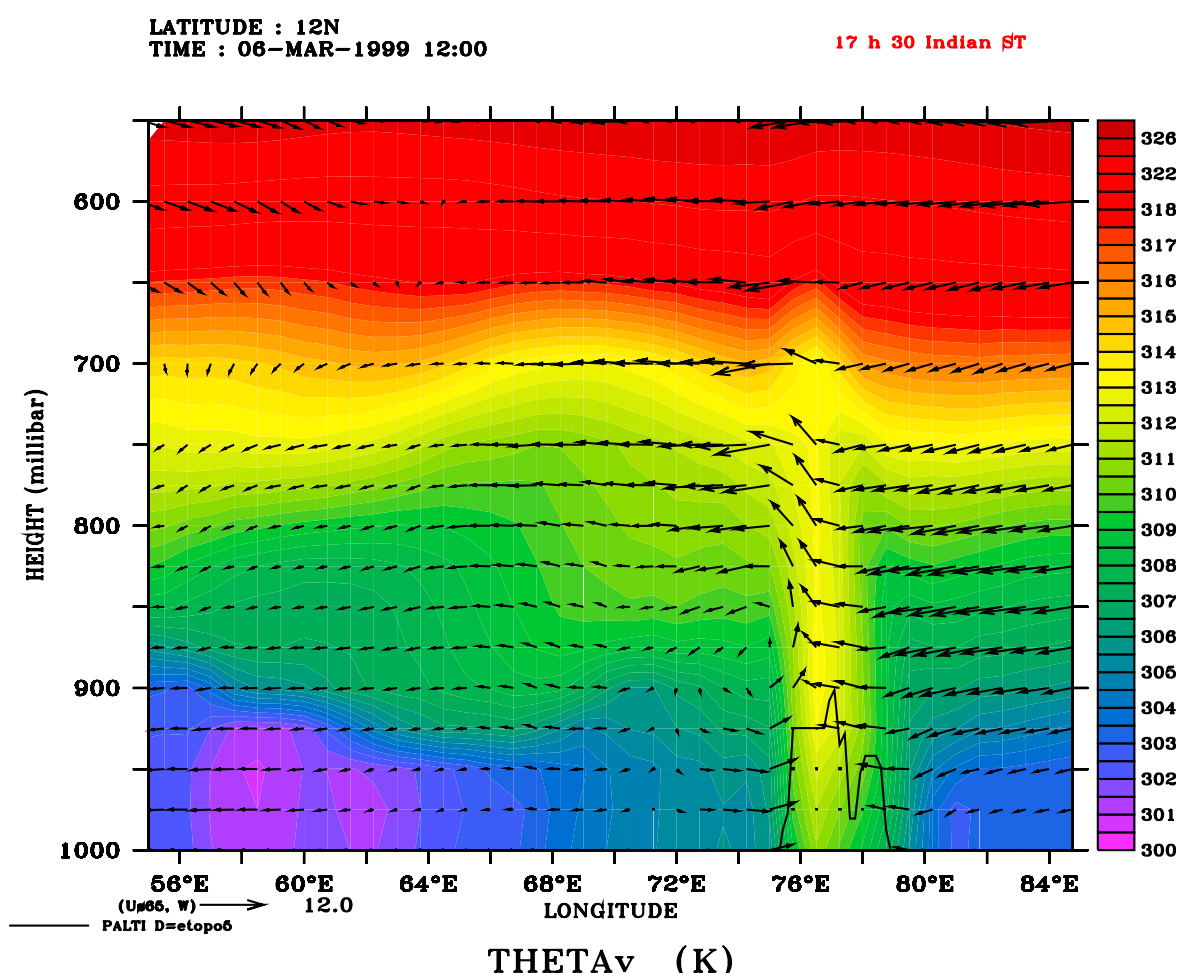

THETAv (K)

Figure 15. Virtual potential temperature THETAv and wind profile along the $12^{\circ} \mathrm{N}$ parallel on 6 March 1999, 1200 UTC, derived from ERA Interim analyses, with the cross section of the Indian peninsula. The wind is composed of a horizontal nearly zonal component (projection onto the $65^{\circ} \mathrm{N}$ axis of the horizontal wind, corresponding to the direction of propagation of the solitary wave) and the analyzed vertical component. Note the presence of the sea breeze cell between $72^{\circ} \mathrm{E}$ and $76^{\circ} \mathrm{E}$, and between the surface and the $850 \mathrm{hPa}$ level.

one sea breeze (on the Indian west coast) into an existing, large-scale flow (northeasterly/easterly winds over the Indian peninsula). Numerical simulations of the collision of sea breezes along the east and west coasts of Cape York in northern Australia can explain the existence and propagation of northeasterly morning glories [Goler and Reeder, 2004]. Such a mechanism cannot explain the formation of the long solitary waves parallel to the West Indian coast. Although the Indian east coast sea breeze could theoretically propagate over several hundreds of kilometers in this tropical region [Yan and Anthes, 1987], a collision with the west coast sea breeze would imply: either (1) a generation of the east coast sea breeze at a single instant (or over a short period) along the Indian east coast; this implies an inland propagation of the east coast sea breeze at variable speed, increasing with latitude toward the north of the approximately V-shaped Indian subcontinent, in order to produce the collision between sea breezes and resulting solitary waves parallel to the West Indian coast; or (2) a propagation at a (nearly) constant speed and a generation at different instants, i.e., later during the day at locations closer to the southern end of the Indian peninsula. Such formation and propagation characteristics implied by the geography of the Indian peninsula for the east coast sea breeze are not realistic.

[66] During the period of this study (2-7 March 1999), solitary waves have been generated during the same period of the day, in the local afternoon, had a similar aspect (line clouds) and orientation, and close locations at the same instants of different days during the first phases of their life. The absence of large convective systems over this geographical area, between $5^{\circ} \mathrm{N}$ and $20^{\circ} \mathrm{N}$, with only a few, very localized exceptions excludes a generation mechanism based on a cold air outflow from thunderstorms.

\subsection{Relation Between Solitary Wave, Moisture, and Sea Breeze}

[67] A feature commonly observed during the studied period (2-7 March 1999) is the difference of the cloud coverage on both sides of the solitary wave clouds during the phase 2 of their lifecycle (Figures 1,2, and 3): fewer clouds are found ahead of the solitary wave. The presence of a drier area ahead of the solitary wave can also be noticed on the dropsonde measurements of relative humidity (Figure 11b). A first possible explanation is that humid air masses are advected by a gravity current (which could in turn generate a solitary wave) or some similar mechanism. This mechanism is not validated by measurements: the solitary wave moves at a higher speed than the wind in the surrounding area. A more realistic mechanism is that the passage of the solitary wave produces vertical air motion and turbulence in its wake, which triggers the formation of low-level cumulus clouds.

[68] In order to explain this mechanism, we also examined ERA-Interim analyzed relative humidity and winds. Cross sections along a parallel show the existence of a diurnal 


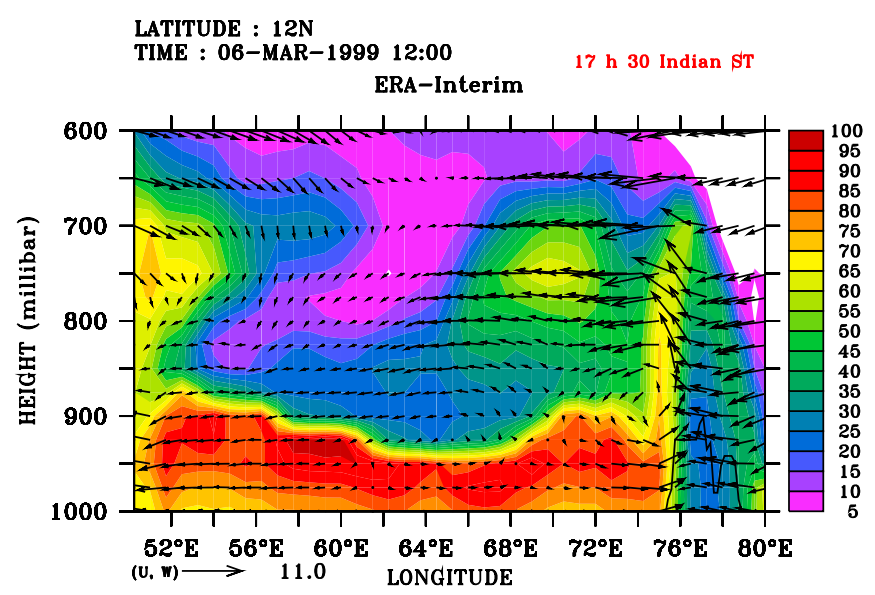

Relative humidity

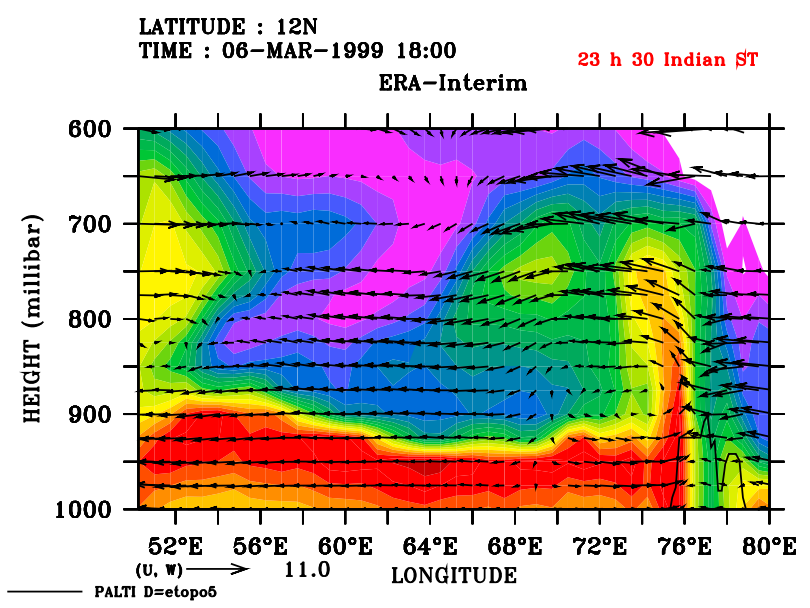

TIME : 07-MAR-1999 00:00

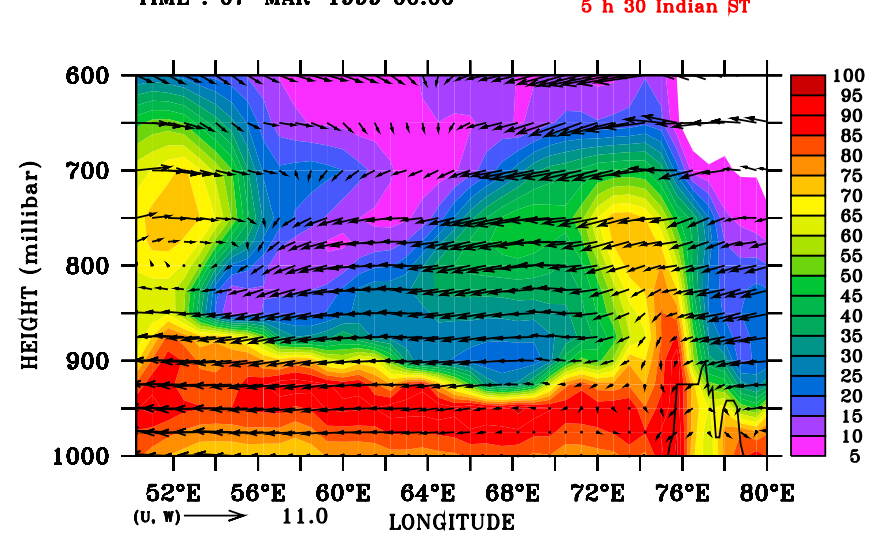

TIME : 07-MAR-1999 06:00

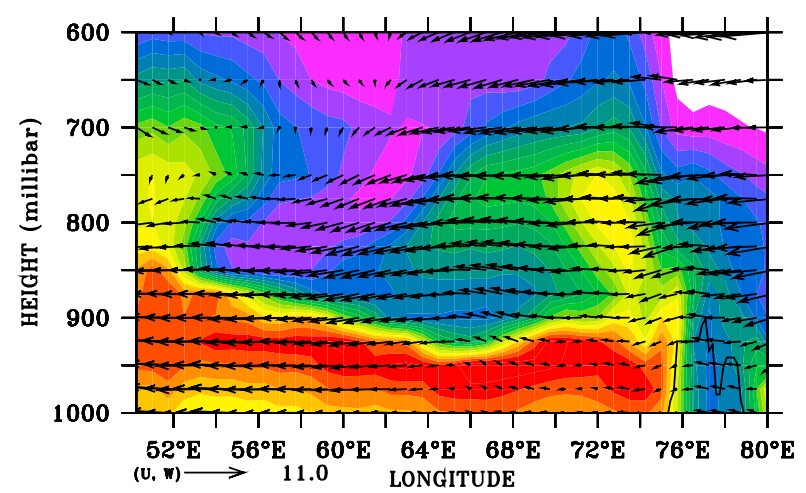

Figure 16. ERA-Interim analyzed relative humidity (\%) and (zonal + vertical) wind $\left(\mathrm{m} \mathrm{s}^{-1}\right)$ field along the $12^{\circ} \mathrm{N}$ parallel, on 6 March at (top left) 1200 UTC (1730 IST) and (top right) 1800 UTC and 7 March at (bottom left) 0000 UTC and (bottom right) 0600 UTC. The West Indian coast is located approximately at $76^{\circ} \mathrm{E}$.

cycle with a generation of a "bubble" of higher relative humidity on the West Indian coast, which then drifts westward and slowly subsides. Figure 16 shows the relative humidity and the wind (zonal and vertical components) fields at the latitude $12^{\circ} \mathrm{N}$. During the local afternoon (1200 UTC, which corresponds to 1730 IST), convection sets on along the Western Ghats range (around $76^{\circ} \mathrm{E}$ ), probably reinforced by the sea breeze circulation, and injects moisture into the dry land plume layer up to a height of $700 \mathrm{hPa}$. In the early night (1800 UTC), convection is reduced, and the related vertical wind decreases. At the end of the night (0000 UTC; 0530 IST), the moisture flow related to the sea breeze is completely stopped and the moisture present in the land plume layer over the coastal area is blown away by the westerly/northwesterly wind as an isolated "bubble" of moisture. Along its westward motion (0600 UTC, and during the following $24 \mathrm{~h}$ ), the bubble undergoes a subsident motion (from $750 \mathrm{hPa}$ to about $850 \mathrm{hPa}$ ) and its relative humidity progressively decreases. Ultimately, the bubble disappears, possibly due to the meridional wind component, or its remnant reaches the top of the marine boundary layer between $55^{\circ} \mathrm{E}$ and $60^{\circ} \mathrm{E}$, and 850 and $900 \mathrm{hPa}$.

[69] This cycle has been observed during the 2-7 March period, when the solitary wave was present, but also on 8 March, a day without wave. Although being apparently generated by the same mechanism, the sea breeze on the West Indian coast, the moisture bubble does not have a direct impact on the solitary wave. It may nevertheless have an indirect impact on the cloud cover where the solitary wave propagates, by reducing the energy which reaches the sea surface and limiting the formation of clouds (in particular during phase 2 of the lifecycle of solitary waves), or contribute to thicken the marine boundary layer on the western part of the North Indian Ocean (west of $60^{\circ} \mathrm{E}$ ) during phases 3 and 4 of the waves' lifecycle. But these effects have to be further investigated.

\section{Discussion and Conclusion}

[70] During this study, we noticed that the solitary waves observed over the North Indian Ocean presented common 
points with the northeasterly morning glories observed over North Australia, but also some differences. Among the common elements, we find the following.

[71] 1. A localization in the tropics and a similar geographical configuration with a peninsula pointing toward the equator (Indian peninsula/Cape York), colliding flows from the east and west coasts in the lower tropospheric levels, mainly during the end of the local winter/beginning of the spring (February-April/September-October).

[72] 2. A west coast sea breeze involved in the generation mechanism, and a westward/southwestward propagating solitary wave.

[73] 3. The presence of favorable conditions for the existence for a waveguide: a stratified layer on which the solitary waves propagate, an almost neutral (mixed) layer above, a mixed layer capping inversion, the curvature of the wind profile, the presence of a layer with a negative Scorer parameter. Note that some of these elements may also be present on days without solitary wave [Menhofer et al., 1997].

[74] On the other hand, some features clearly differentiate North Indian Ocean solitary waves and morning glories:

[75] 1 . The presence of a stable and relatively well-mixed marine boundary layer with a thickness of 500-1000 m over the northern part of the Indian Ocean. This layer is topped by a stratified inversion layer on which the solitary wave propagates, where the linear wave clouds are located and where small cumulus sometimes form. Morning glories propagate on a shallow, surface-based stable layer, and the associated roll clouds are located at a lower altitude, typically $200-300 \mathrm{~m}$. This shallow stable layer is present at night; it is progressively destroyed by convection over land during daytime.

[76] 2. The presence of an extended oceanic area, with relatively well-defined and persistent atmospheric layers during the day and the night, enable a long-lasting propagation of solitary waves over the North Indian Ocean, up to two entire days. Northeasterly morning glories can only propagate during a short time, mainly during nighttime, over the Gulf of Carpentaria before reaching Australian land again. Over land they can only propagate at best during the morning following their formation. Generally at noon, convection has destroyed the stable layer which supports morning glory propagation [Clarke, 1989].

[77] 3. Other factors, such as topography (low mountain ridges with a dominant north-south orientation, along the western/eastern coast of the peninsula), the presence of a reduced wind component/opposing winds at low level and in the middle troposphere (above $4 \mathrm{~km}$ ) have also been noticed. But these factors do not lead to radical differences between both phenomena.

[78] Among the observed phenomena and the related mechanisms leading to the formation of solitary waves, northerly morning glories appear to be the most closely related to the solitary waves observed over the North Indian Ocean.

[79] In this study, we have completed the description of a mesoscale low-level solitary wave phenomenon identified during the INDOEX experiment in 1999. Five phases have been identified on series of Meteosat satellite images: (1) a formation phase of a line cloud characteristic of the solitary wave; (2) a phase of propagation in relatively cloud-free area, where a long, clearly identified line cloud is present, in some locations and at some instants followed by parallel secondary line clouds; ( 3 and 4 ) the solitary wave propagates in low-level cloud (marine cumulus) areas and remains visible by locally reinforcing convection; and (5) a dissipation phase, when a broad band of low-level cloud, which is the remainder of the attenuated solitary wave, becomes undistinguishable from other surrounding clouds. Including the generation phase prior to their detection on satellite images, solitary waves observed during the 3-7 March 1999 period have in some cases lasted more than $48 \mathrm{~h}$, an exceptionally long lifetime in comparison to other similar phenomena, such as morning glories, or waves resulting from the demise of thunderstorms, or waves ahead of fronts. We noticed a small increase of the speed of solitary waves along their trajectory, in some cases with periods of stable speed (on 6 March 1999: during daytime). The horizontal wavelength of $10-15 \mathrm{~km}$, derived from the first wave pattern cloud positions, also increases with time.

[80] We identified a key element on dropsonde potential temperature and wind profiles: the waveguide structure enabling the propagation of the solitary wave. The dual sublayer structure of the boundary layer over the ocean has already been identified by other authors; i.e., a well-mixed marine boundary layer between the sea surface and a height between 700 and $1100 \mathrm{~m}$, topped by a second layer of relatively well-mixed air advected from the Indian subcontinent, the land plume layer, reaching an altitude of approximately $3000 \mathrm{~m}$. The analysis of the Scorer parameter profile showed that vertical propagation of the wave is only possible in the thin layer around an altitude of about $1 \mathrm{~km}$ (corresponding to the inversion layer) where the solitary wave must be located. This waveguide structure limits energy dissipation on the vertical and thus allows a horizontal propagation of the wave over a longer time.

[81] Solitary waves cannot be observed in all circumstances. In particular, line clouds or alignments of small cumulus clouds can act as revealing tracers only if enough moisture is present locally when the wave is in motion. This may explain why the wave structure is not observed on satellite images just after its formation, or why secondary line clouds are not present.

[82] The daily apparition of a solitary wave over the same, limited area and a longitudinal shape approximately parallel to the West Indian coast during the first phases of its life suggested a generation mechanism in relation to the coastal profile, and sea or land breezes seemed good candidates. The propagation speed of precursors, the edge of low-level cloud layers $\left(\sim 15 \mathrm{~m} \mathrm{~s}^{-1}\right.$ on 6 March, corresponding to the 7 March case), is compatible with the speed derived later from the well-established and observed wave clouds. The only mechanism able to generate a solitary wave with such a propagation speed (or with a close value) had to be related to the sea breeze of the previous day along the West Indian coast.

[83] We suggest as generation mechanism of solitary waves the collision between the landward sea breeze flow (from the west/southwest) with the dominant inland winter monsoon flow (from the east/northeast), probably in the middle of the local afternoon. We could not determine the exact mechanism and timing of the collision of opposite flows from the available data. But we noticed that the sea 
breeze flow brings important quantities of moisture inland, which on the other hand contribute to or enhance the formation of the cumulus clouds visible on satellite images at approximately $100 \mathrm{~km}$ from the coast, along the Western Ghats range. Related orography may also play a role by triggering convection or locally channeling the sea breeze flow. After the collision, the solitary wave moves westward, first atop the sea breeze cell, and later on top of the marine boundary layer. Farther west, during phase 2, the solitary wave exhibits the characteristics of an undular bore. At this stage it cannot be a gravity wave.

[84] North Indian Ocean solitary waves show important similarities with northeastern morning glories observed over North Australia: the geographical configuration (a peninsula), the season and the presence of a sea breeze implied in the generation mechanism. The major difference is their lifetime: under favorable conditions, North Indian Ocean solitary waves can move freely over the ocean for several hundreds of kilometers and during more than one day, whereas northeasterly morning glories reach land again relatively quickly (on the next morning) after their generation, where the convection during daytime eventually destroys the stable layer on which they propagate.

[85] Propagating solitary waves can destabilize air masses locally, and thus waves can trigger or increase convection in their wake in relatively cloud-free areas. This phenomenon, obvious during phase 2 , leads to an increased cloud coverage of low-level clouds (mainly cumulus). Therefore, solitary waves have and indirect impact on the radiative balance by reducing energy received over parts over the North Indian Ocean.

[86] This study also helped to determine parameters characterizing favorable conditions for the existence and propagation of solitary waves. In the first, DSPD2003 study, the presence of weak winds at low level $(925 \mathrm{hPa})$ off the southwestern Indian coast, and the existence of winds with a northerly component close to the northwestern Indian coast has been observed as favorable conditions. In the current, we add two characteristic elements: the waveguide located between the marine boundary layer and the land plume layer, on which the wave propagates, and the joint presence of the sea breeze cell along the West Indian coast and a northeasterly/easterly circulation over the Indian subcontinent. Note that these newly determined characteristics are necessary, but may also be present on days without observed solitary waves (for example on 8 March).

[87] Some questions arise after this study, about the causes and conditions of the dissipation of solitary waves, and about the exact mechanism of the collision between the sea breeze and the continental flow in the boundary layer. An unexpected result is the observation of bubbles of moisture (on ERA-Interim analyses), injected daily by the sea breeze into the land plume layer, and which drift westward over the ocean before subsiding or dissipating. Their influence on the local meteorology, in particular on solitary wave motion and cloud formation (if any) has yet to be determined. Further studies are needed to answer these questions.

\section{Appendix A: Construction of Cloud Trajectories}

[88] Trajectories of different portions of solitary waves are calculated by two different methods from series of consec- utive geostationary images, in our case from Meteosat-5, in the visible (VIS) and thermal infrared (IR) channels. In the first DSPD 2003 study, solitary wave trajectories were constructed only with an automated cloud tracking method. In order to increase the duration of trajectories, we developed a "manual" tracking method, based on the visual identification and tracking of a selected part of a solitary wave. The principle and limitations of both methods are presented and compared hereafter.

\section{A1. Automatic Cloud Tracking Method}

[89] Solitary waves trajectories are constructed in the first place with a technique derived from methods used to calculate cloud motion winds from triplets of satellite image, which has been extended to series of images that may cover several days. This method consists in matching a given square of pixels $(32 \times 32$ in the VIS, $24 \times 24$ in the IR channel of Meteosat) containing a part of the cloud line to track on a pair of images, according to a statistical criterion: the difference in position of the square of pixels, given by the minimum of the sum-of-squared difference (Euclidean distance) of the pixel values, determines the motion of the tracked cloud structure. Starting on the match position on the second image, the process is then repeated between this image and the next one of the series. The new derived motion vector is compared to the one obtained during the previous step. If both vectors are consistent (i.e., realistic and having a close amplitude and direction), this process is iterated on the following images of the series. An interruption of the trajectory, due to inconsistent consecutive motion vectors is generally the result of the dissipation of the tracked cloud, or the formation or superposition of a new or a more important or influent cloud [Szantai et al., 2002].

[90] In practice, two trajectories are calculated automatically for each position in the IR channel. The start image that we selected is the 0330 UTC image of the day. At this time (corresponding to 0900 IST), the cloud line associated with the solitary wave is well-formed and easy to track. First, a direct trajectory is derived from the following images. Practically, the tracking algorithm cannot extract trajectories beyond 1830 UTC, because several consecutive images are systematically missing during this period of the year (eclipse period of the satellite around equinox). In a second step, a backward trajectory is derived from the previous images as long as possible, down to the 2100 UTC image of the day before (the previous images correspond again to the eclipse period). In the last step, a complementary test then compares the first vector of the direct and backward trajectory (temporal consistency test): if the vectors are opposite (or very close to it), the complete trajectory resulting from the association of both direct and backward trajectory is validated. Note that VIS images are only available during daytime, thus the duration of trajectories in this channel, starting at 0330 UTC, is practically limited to $9 \mathrm{~h}$ and no backward trajectory is calculated. For clarity reasons, only the direct trajectory part has been represented in Figure 3.

\section{A2. "Manual" Tracking Method}

[91] In order to overcome the interruption of the tracking due to the missing images between 1830 and 2030 UTC, 
and also the impossible automated tracking of some cumulus clouds with a slightly different morphology due to the passage of the solitary wave among a vast area of other "normal" ones, we manually reconstructed their trajectory. For this purpose, significant cloud elements associated with the solitary wave are visually located on a computer screen, are marked with a mouse, and geographically navigated. This process is iterated on the series of images as long as a visual identification of these elements is possible. Figure 3 shows such trajectories (in green, yellow and orange) can reach the western part of the North Indian Ocean. These trajectories are approximately extensions of the ones calculated first, with the automatic method (in pink). Visual tracking enables the tracking of clouds associated with solitary waves over longer distances and with a more complex cloud cover. This "manual" method is nevertheless unable to reconstruct the final stage of the progression of the solitary wave and to determine its main characteristics (position and velocity). Only a human operator can visually observe and follow varying and aligned fluctuations of clouds on consecutive images. For example, at the end of the 3 March case, the remaining tenuous clouds associated with the wave form a line that crosses the already mentioned long line cloud in the vicinity of the Arabian peninsula and "survives" to this encounter (around 0500 UTC on 4 March), before disappearing completely in the vicinity of the coast (at about 1030 UTC).

\section{A3. Quality of the Wave Trajectories}

[92] The automatic method proved to work efficiently during phase 2 and the beginning of phase 3 of the solitary wave lifecycle (propagation in a relatively cloud-free area), whereas the manual method was also able to track the waves during phase 3 (propagation in low-level cloud areas) and partly during phase 4 (propagation during the second night and day).

[93] For the automatic tracking method, the measurement error is 0.5 pixel for a trajectory vector in each direction (line and column of the image). This corresponds to an error on the wave speed of $1.25 \mathrm{~m} \mathrm{~s}^{-1}$ at subsatellite point for Meteosat IR images $\left(0.63 \mathrm{~m} \mathrm{~s}^{-1}\right.$ for VIS images).

[94] For the manual tracking method, the measurement error is probably larger, but more difficult to estimate. It is operator-dependent: measurements of cloud motion may not be the same for different operators, and may depend from personal factors such as experience, tiredness, etc. In order to reduce fluctuations on the wave-cloud motion measurement resulting from the tracking process, a running mean covering 3 consecutive vectors is applied, thus the resulting trajectories are smoother.

[95] The direction of the wave motion, in our case materialized by one or several longitudinal clouds, should be orthogonal to the cloud orientation. This is also what is observed on images with superimposed trajectories (Figure 3) and on movie loops. But some small lateral variations of motion (parallel to the cloud orientation) are present, making trajectories less regular and leading in some cases to the intersection of two trajectories. This may be the signature of the "aperture effect" well known in image processing: if only a segment of a straight structure is tracked, then the only component of motion that can be determined is the one normal to the structure. In our case, the lateral motion com- ponent may be due to the presence of other clouds in the vicinity moving with a different motion, or the dissipation or enhanced formation at one end of the wave cloud. The effect of this lateral motion component is nevertheless small on the overall motion, it may increase slightly the related velocity.

[96] Acknowledgments. AVHRR images and measurement data from the R.V. Ron Brown and from the Hercules C-130 aircraft were provided by the INDOEX community, via the JOSS-UCAR database. Meteosat images from EUMETSAT and ERA-Interim reanalyses from the European Centre of Medium-Range Weather Forecast (ECMWF) were made available on the ClimServ database of the French Institut Pierre Simon Laplace (IPSL).

\section{References}

Bieringer, P. E., B. Martin, B. Collins, and J. Shaw (2004), Commercial aviation encounters with severe low altitude turbulence, paper presented at 11 th Conference on Aviation, Range and Aerospace Meteorology, Am. Meteorol. Soc., Hyannis, Mass.

Christie, D. R. (1989), Long nonlinear waves in the lower atmosphere, J. Atmos. Sci., 46, 1462-1491, doi:10.1175/1520-0469(1989)046<1462: LNWITL $>2.0 . \mathrm{CO} ; 2$.

Christie, D. R. (1992), The morning glory of the Gulf of Carpentaria: A paradigm for non-linear waves in the lower atmosphere, Aust. Meteorol. Mag., 41, 21-60.

Christie, D. R., K. J. Muirhead, and R. H. Clarke (1981), Solitary waves in the lower atmosphere, Nature, 293, 46-49, doi:10.1038/293046a0.

Clarke, R. H. (1972), The Morning glory: An atmospheric hydraulic jump, J. Appl. Meteorol., 11, 304-311, doi:10.1175/1520-0450(1972) 011<0304:TMGAAH $>2.0 . \mathrm{CO} ; 2$.

Clarke, R. H. (1984), Colliding sea-breezes and the creation of internal atmospheric bores waves: Two dimensional numerical studies, Aust. Meteorol. Mag., 32, 207-226.

Clarke, R. H. (1989), On the mortality of morning glories, Aust. Meteorol. Mag., 37, 167-172.

Crook, N. A. (1986), The effect of ambient stratification and moisture on the motion of atmospheric undular bores, J. Atmos. Sci., 43, 171-181, doi:10.1175/1520-0469(1986)043<0171:TEOASA > 2.0.CO;2.

Crook, N. A. (1988), Trapping of low-level internal gravity waves, J. Atmos. Sci., 45, 1533-1541, doi:10.1175/1520-0469(1988)045<1533: TOLLIG $>2.0 . \mathrm{CO} ; 2$

da Silva, J. C. B., and J. M. Magalhães (2009), Satellite observations of large atmospheric gravity waves in the Mozambique Channel, Int. J. Remote Sens., 30, 1161-1182, doi:10.1080/01431160802448943.

Dekate, M. V. (1968), Climatological study of sea and land breezes over Bombay, Indian J. Meteorol. Geophys., 19, 421-426.

Désalmand, F., A. Szantai, L. Picon, and M. Desbois (2003), Systematic observation of westward propagating cloud bands over the Arabian Sea during the Indian Ocean Experiment (INDOEX) from Meteosat-5 data, J. Geophys. Res., 108(D18), 8004, doi:10.1029/2002JD002934.

Egger, J. (1984), On the theory of the morning glory, Beitr. Phys. Atmos., $57,123-134$.

Forêt, G., C. Flamant, S. Cautenet, J. Pelon, F. Minvielle, M. Taghavi, and P. Chazette (2006), The structure of the haze plume over the Indian Ocean during INDOEX: Tracer simulations and lidar observations, Atmos. Chem. Phys., 6, 907-923, doi:10.5194/acp-6-907-2006.

Fulton, R., D. S. Zrnic, and R. J. Doviak (1990), Initiation of a solitary wave family in the demise of a nocturnal density current, J. Atmos. Sci., 47, 319-337, doi:10.1175/1520-0469(1990)047<0319: IOASWF $>2.0 . \mathrm{CO} ; 2$.

Goler, R. A., and M. J. Reeder (2004), The generation of the morning glory, J. Atmos. Sci., 61, 1360-1376, doi:10.1175/1520-0469(2004) 061<1360:TGOTMG>2.0.CO;2.

Koch, S. E., W. Feltz, F. Fabry, M. Pagowski, B. Geerts, K. Bedka, D. O. Miller, and J. W. Wilson (2008), Turbulent mixing processes in atmospheric bores and solitary waves deduced from profiling systems and numerical simulation, Mon. Weather Rev., 136, 1373-1400, doi:10.1175/2007MWR2252.1.

Leon, J.-F., et al. (2001), Large-scale advection of continental aerosols during INDOEX, J. Geophys. Res., 106(D22), 28,427-28,439, doi:10.1029/ 2001JD900023.

Menhofer, A., R. K. Smith, M. J. Reeder, and D. R. Christie (1997), "Morning glory" disturbances and the environment in which they propagate, J. Atmos. Sci., 54, 1712-1725, doi:10.1175/1520-0469(1997) 054<1712:MGDATE $>2.0 . \mathrm{CO} ; 2$.

Ramanathan, V., et al. (1995), INDOEX White Paper: Indian Ocean Experiment, Publ. 143, Cent. for Clouds, Chem. and Clim., Scripps Inst. of 
Oceanogr., La Jolla, Calif. (Available at http://www-indoex.ucsd.edu/ publications/white_paper/)

Ramanathan, V., et al. (2001), Indian Ocean Experiment: An integrated analysis of the climate forcing and effects of the great Indo-Asian haze J. Geophys. Res., 106(D22), 28,371-28,398, doi:10.1029/ 2001JD900133.

Romanova, N. N., and I. G. Yakushkin (1995), Internal gravity waves in the lower atmosphere and sources of their generation (review), Atmos. Oceanic Phys., 31, 151-172.

Rottman, J. W., and F. Einaudi (1993), Solitary waves in the atmosphere, J. Atmos. Sci., 50, 2116-2136, doi:10.1175/1520-0469(1993)050<2116: SWITA $>2.0 . \mathrm{CO} ; 2$.

Rottman, J. W., and R. Grimshaw (2002), Atmospheric internal solitary waves, in Environmental Stratified Flows, edited by R. Grimshaw, pp. 61-88, Kluwer Acad., Norwell, Mass.

Scorer, R. S. (1949), Theory of waves in the lee of mountains, $Q . J . R$ Meteorol. Soc., 75, 41-56, doi:10.1002/qj.49707532308.

Simpson, J. E. (1994), Sea Breeze and Local Winds, 2nd ed., 234 pp., Cambridge Univ. Press, Cambridge, U. K.

Simpson, M. D., and S. Raman (2004), Role of the land plume in the transport of ozone over the ocean during INDOEX (1999), Boundary Layer Meteorol., 111, 133-152, doi:10.1023/B:BOUN.0000010993.46250.b2.

Smith, R. K. (1988), Travelling waves and bores in the lower atmosphere: The 'morning glory' and related phenomena, Earth Sci. Rev., 25, 267-290, doi:10.1016/0012-8252(88)90069-4.

Smith, R. K., M. J. Reeder, N. T. Tapper, and D. R. Christie (1995), Central Australian cold fronts, Mon. Weather Rev., 123, 16-38, doi:10.1175 1520-0493(1995)123<0016:CACF $>2.0 . \mathrm{CO} ; 2$.

Subrahamanyam, D. B., K. Sen Gupta, S. Ravindran, and P. Krishnan (2001), Study of sea breeze and land breeze along the west coast of
Indian sub-continent over the latitude range $15^{\circ} \mathrm{N}$ to $8^{\circ} \mathrm{N}$ during the INDOEX IFP-99(SK-141) cruise, Curr. Sci., 80, suppl., 85-88.

Subrahamanyam, D. B., R. Ramachandran, K. Sen Gupta, and T. K. Mandal (2003), Variability of mixed-layer heights over the Indian Ocean and central Arabian Sea during INDOEX, IFP-99, Boundary Layer Meteorol., 107, 683-695, doi:10.1023/A:1022811512160.

Szantai, A., F. Désalmand, and M. Desbois (2002), A method for the construction of cloud trajectories from satellite images, Int. J. Remote Sens., 23(8), 1699-1732, doi:10.1080/01431160110075541.

Verver, G. H. L., D. R. Sikka, J. M. Lobert, G. Stossmeister, and M. Zachariasse (2001), Overview of the meteorological conditions and atmospheric transport processes during INDOEX 1999, J. Geophys. Res., 106(D22), 28,399-28,413, doi:10.1029/2001JD900203.

Yan, H., and R. Anthes (1987), The effect of latitude on the sea breeze, Mon. Weather Rev., 115, 936-956, doi:10.1175/1520-0493(1987) $115<0936$ :TEOLOT $>2.0 . \mathrm{CO} ; 2$.

Zheng, Q., X.-H. Yan, W. T. Liu, V. Klemas, D. Greger, and Z. Wang (1998a), A solitary wave packet in the atmosphere observed from space, Geophys. Res. Lett., 25, 3559-3562, doi:10.1029/98GL02319.

Zheng, Q., X.-H. Yan, V. Klemas, C.-R. Ho, N.-J. Kuo, and Z. Wang (1998b), Coastal lee waves observed on ERS-1 SAR images, J. Geophys. Res., 103(C4), 7979-7993, doi:10.1029/97JC02176.

F. Désalmand, Laboratoire de Météorologie Dynamique/IPSL, Université Pierre et Marie Curie, F-75252 Paris, France.

P. Drobinski and A. Szantai, Laboratoire de Météorologie Dynamique/ IPSL, Ecole Polytechnique, F-91128 Palaiseau, France. (szantai@lmd. polytechnique.fr) 